\title{
CAN HELPING THE SICK HURT THE ABLE? INCENTIVES, INFORMATION AND DISRUPTION IN A DISABILITY-RELATED WELFARE REFORM
}

\author{
Nitika Bagaria \\ Barbara Petrongolo \\ John Van Reenen \\ Working Paper 21163 \\ http://www.nber.org/papers/w21163
}

\author{
NATIONAL BUREAU OF ECONOMIC RESEARCH \\ 1050 Massachusetts Avenue \\ Cambridge, MA 02138
}

May 2015

We would like to thank the ESRC for funding this research through the Centre for Economic Performance Richard Disney, Victor Lavy, Alan Manning, Steve Pischke, Bill Wells and participants at seminars in IFS, LSE, NBER and NIESR have given helpful comments. Barra Roantree generously provided some of the estimates of benefit receipt. The views expressed herein are those of the authors and do not necessarily reflect the views of the National Bureau of Economic Research.

NBER working papers are circulated for discussion and comment purposes. They have not been peerreviewed or been subject to the review by the NBER Board of Directors that accompanies official NBER publications.

(C) 2015 by Nitika Bagaria, Barbara Petrongolo, and John Van Reenen. All rights reserved. Short sections of text, not to exceed two paragraphs, may be quoted without explicit permission provided that full credit, including $(\mathcal{C}$ notice, is given to the source. 
Can helping the sick hurt the able? Incentives, information and disruption in a disability-related welfare reform

Nitika Bagaria, Barbara Petrongolo, and John Van Reenen

NBER Working Paper No. 21163

May 2015

JEL No. H53,I13,I38,J14,J18,J64

\begin{abstract}
Disability rolls have escalated in developed nations over the last 40 years. The UK, however, stands out because the numbers on these benefits stopped rising when a welfare reform was introduced that integrated disability benefits with unemployment insurance (UI). This policy reform improved job information and sharpened bureaucratic incentives to find jobs for the disabled (relative to those on UI). We exploit the fact that policy was rolled-out quasi-randomly across geographical areas. In the long-run the policy improved the outflows from disability benefits by $6 \%$ and had an (insignificant) $1 \%$ increase in unemployment outflows. This is consistent with a model where information helps both groups, but bureaucrats were given incentives to shift effort towards helping the disabled find jobs and away from helping the unemployed. Interestingly, in the short-run the policy had a negative impact for both groups, suggesting important disruption effects. We estimate that it takes about six years for the estimated benefits of the reform to exceed its costs, which is beyond the time horizon of most policy-makers.
\end{abstract}

Nitika Bagaria

Centre for Economic Performance, LSE

Houghton Street

London WC2A 2AE

UNITED KINGDOM

n.bagaria@lse.ac.uk

Barbara Petrongolo

Centre for Economic Performance, LSE

Queen Mary University and CEPR

Mile End Road

London E1 4NS

UNITED KINGDOM

B.Petrongolo@1se.ac.uk
प

John Van Reenen

London School of Economics

Centre for Economic Performance $\mathrm{DOQ} 1$ \% 5 (

Houghton Street

London WC2A 2AE

UNITED KINGDOM

j.vanreenen@1se.ac.uk 


\section{Introduction}

Disability rolls have risen almost inexorably in the advanced nations over the last forty years (e.g. Autor and Duggan, 2003). In the US, Social Security Disability Insurance (SSDI) cash transfers have tripled from $\$ 40 \mathrm{bn}$ in 1979 to $\$ 124 \mathrm{bn}$ in 2010, and their share of total social security payments rose from 10\% in 1988 to $20 \%$ in 2009 (Autor, 2012). Figure 1 shows that the numbers on the equivalent UK scheme, Incapacity Benefit (IB), also rose spectacularly from 400,000 in 1977 to $2 \mathrm{~m}$ in 2009 for those of working age. ${ }^{4}$ Unlike the US, however, the UK increase seemed peak in early 2000s and then fall slightly. This coincided with the introduction of a major policy reform in 2001 where the agencies responsible for employment services and welfare benefits for working age people were merged into one organization, "Jobcentre Plus". There was an emphasis on improving job search assistance and monitoring for IB recipients, something that had already been happening for UI claimants since the mid-1980s (e.g. Van Reenen, 2004).

The welfare reform physically integrated the offices where welfare claimants go to have work-focused interviews, collect checks and look for jobs. It simultaneously increased information and changed bureaucratic incentives, without changing the financial generosity of the welfare system. Information was improved for all groups by a major new IT system and new buildings. Incentives for bureaucrats in charge of helping welfare claimants find jobs were changed, via an explicit points system that awarded three times as many points for helping a disabled person into work than for helping an unemployed person. These points fed into career progression for local bureaucrats.

In our empirical analysis we exploit the staggered roll-out of the Jobcentre Plus policy across geographical areas, using quarterly administrative data on over 400 UK districts over a nine year period. ${ }^{5}$ We identify the policy impact by comparing the change in exit rates for disability and unemployment benefit claimants in districts treated at a point in time to that in districts treated at an earlier or later date. Information on benefit claimants at the district level is provided by the Department for Work and Pensions, and we use quarterly series for stocks, inflows and outflows for various categories of welfare benefits, disaggregated by age and

\footnotetext{
${ }_{5}^{4}$ See Banks et al. (2015) for benefit trends in the UK and related reforms.

${ }^{5}$ UK districts are similar to US counties. The average population of a district was 120,000 in the 2001 census. In comparison, the average population of a US county is around 100,000 people.
} 
district, and, for the unemployed, also disaggregated by destination (e.g. to employment versus non-participation).

We find two main results. First, there were significant organizational disruption costs from the policy, with outflows from disability and unemployment benefits initially declining after the policy change, and more markedly so for the unemployed than the disabled. Second, in the long-run there are significant positive effects on disabled outflows, whereas unemployment outflows (although also positive) are small and insignificant. These patterns are consistent with a simple model whereby bureaucratic efforts to reduce disabled rolls increased, but efforts to reduce unemployment rolls decreased. However, overlaid on this there was a long-term positive effect on both groups from better information but a short-run negative effect from adjustment costs due to organizational disruption.

Based on our estimates, we provide a simple cost-benefit analysis of Jobcentre Plus that indicates positive net benefits from the policy. However, the presence of significant short-run costs from disruption and sunk set-up costs highlights why such welfare changes are hard to implement. We estimate that it takes about six years for the reform to break even, which is beyond the time horizon of most policy-makers.

This paper links to two main strands of literature. First, the issue of welfare reforms has resurfaced following the Great Recession of 2008-2009. For example, increases in unemployment were much lower than expected in the $\mathrm{UK}^{6}$ and Germany, and both countries experienced significant welfare reforms prior to the crisis. A body of work in the welfare literature has studied the effects of financial incentives to benefit recipients on the duration of unemployment (e.g. Lalive et al, 2007), while the role of explicit incentives in the provision of job placement services has been less of a focus. Another strand of this literature has emphasized the interplay between unemployment and disability insurance, as some job losers may turn to disability benefits once they are no longer eligible for unemployment benefits. For the UK, Petrongolo (2009) finds that welfare recipients subject to stricter job search requirements were more likely to start spells on health-related benefits within six months of the end of a claimant unemployment spell, while Mueller et al. (2013) find no evidence that expiry of unemployment benefits raised applications for disability benefits in the US over the Great Recession. By

\footnotetext{
${ }^{6}$ On the UK case see Blundell, Crawford and Jin (2014), Gregg, Machin and Salgado (2014) and Pessoa and Van Reenen (2014).
} 
contrast, our work explores links between unemployment and disability insurance stemming from job placement, rather than jobseekers' incentives.

Second, a growing literature has highlighted how incentive systems can be used to improve efficiency, particularly in the public sector (e.g. on the theory see Besley and Ghatak, 2005; and on empirics Meyer, 1995 and Bloom and Van Reenen, 2011, have surveys). Heckman et al. (2011) found bureaucrats' rewards affected cream skimming and showed significant differences between short run and long-run programme impacts. We contribute to this literature by emphasizing the multitasking aspects in the provision of effort in government organizations.

The paper is organized as follows. In section 2 we describe the institutional framework in the UK and the hypotheses we test, in section 3 we outline the data used in the empirical analysis, while in section 4 we report the analysis and results of how the treatment impacts inflows into and outflows from different benefit categories. In section 5 we examine the robustness of our results to different specifications and in section 6 we perform a simple costbenefit evaluation of Jobcentre Plus. Section 7 concludes.

\section{The Institutional Framework}

\subsection{The Jobcentre Plus system}

There were major changes in the delivery of public employment and benefit services in the UK between 2001 and 2008. The change was part of a wider policy emphasis on Welfare-to-Work initiatives $^{7}$ that sought to increase labour market activity. In March 2000, the Prime Minister announced the establishment of the Jobcentre Plus (JCPlus) organization, with the scope to deliver an integrated, work-focused service to both employers and benefit claimants of working age in UK. The creation of Jobcentre Plus stemmed from the integration of the Employment Service and Benefits Agency into one organization, combining benefit advice with job placement services. The integration took place in six waves between 2001 and $2008 .^{8}$

\footnotetext{
7 The guiding principle of these welfare reforms was "work for those who can and security for those who cannot" (Hyde et al., 2002).

${ }^{8}$ Links between benefits and work search in the UK had been introduced with Restart Programme in 1986 (Dolton and O'Neill, 1996, 2002) and were deepened with the introduction of the Jobseekers Allowance in 1996, and the New Deal for Young People in 1998 (see Manning, 2009, Petrongolo, 2009, Blundell et al, 2004, and Van Reenen, 2004 for a history of these developments). Mandatory work-focused interviews were in place for JSA recipients since 1996, well before the introduction of Jobcentre Plus (see Pointer and Barnes, 1997).
} 
Two main changes resulted from the introduction of Jobcentre Plus, relating broadly to information and incentives. On the information side, the integration of employment services and welfare checks under one roof was accompanied by a massive investment in improved information technology (IT) and organizational restructuring. The average size of an office was increased as buildings were combined, re-built, and offices refurbished. Aggregate floor space decreased by $20 \%$ as did the total number of staff, even though operating costs per square meter increased by $12 \%$ because of high quality infrastructure and locations. Overall, the sunk costs of re-organization were around $£ 1.8 \mathrm{bn}$ (about $\$ 2.7 \mathrm{bn}$ ), but running costs were reduced by $£ 240 \mathrm{~m}$ per year (National Audit Office, 2008).

The second major change was the introduction of explicit performance targets called Job Entry Targets. As opposed to the previous system of national-level targets for the number of beneficiaries to place into jobs, under the new regime every benefit officer who helped a benefit claimant into a job was awarded a certain number of explicit Job Entry Target points varying by the category of the benefit claimant. In addition, there was a district-level target in terms of the number of points to achieve each quarter. These performance standards acted like a performance benchmark for the managers and mattered for the career prospects of the benefit officers. ${ }^{9}$

\subsection{Framework}

One can theoretically expect at least three different effects of JCPlus on job placement. Firstly, the physical reorganization, installation of new IT systems and estate rationalization caused disruption. This would lead to a short-run reduction in the productivity of welfare officers. We expect the disruption effect to be broadly similar across all benefit groups (and test this assumption), and to decay over time as officers settle into the new system.

Second, there may a long-run impact of restructuring and modern IT systems on efficiency. IT would facilitate various manual tasks such as recording job entries and keeping

\footnotetext{
${ }^{9}$ The UK welfare system had introduced performance benchmarking since the early 1980s (Propper and Wilson 2003; Bagaria et al, 2013). They have been designed according to targets embodied in the Public Service Arrangements (PSAs) of different government agencies. Makinson (2000) describes the performance standards in the Employment Service, The Benefits Agency, HM Customs and Excise and Inland Revenue. These mostly consisted of national-level targets for the number of beneficiaries to place into jobs, without explicit rewards at the individual or local level. The US welfare system has also introduced elements of performance pay within the recent US Ticket to Work (TTW) Program, providing job placement and ongoing employment support to disability insurance recipients. TTW service providers become eligible for payments from the Social Security as soon as beneficiaries receive earnings above a certain threshold.
} 
records of beneficiaries. Increased automation of services would improve the speed and accuracy with which benefits applications are processed. This reduces operating costs as well as the time officers spend on these back office functions, and enables them to focus on conducting more client-facing job finding interviews. Thus, we expect a long-run increase in job placements for all benefit groups, as the provision of welfare services becomes more efficient. Again, this effect should be broadly similar across all benefit recipients.

Thirdly, the introduction of Job Entry Targets implies a shift in bureaucratic incentives in favour of Incapacity Benefit (IB, the main disability benefit) claimants at the expense of the unemployed claimants. Before the introduction of JCPlus, there were broad national level targets for job placements and sub-targets for different benefit categories. For example, in 2001 there was a national target to place $1.36 \mathrm{~m}$ jobless people into work, accompanied by a sub-target to place 275,000 "disadvantaged" individuals into work. ${ }^{10}$ With the JCPlus policy explicit award points were introduced under the new Job Entry Target system that were designed to reflect prioritizing IB claimants. As shown in Table A1, a benefit officer was awarded fifty per cent more points if he/she placed a person on Incapacity Benefit ${ }^{11}$ into a job than a long-term JSA beneficiary, and three times more points relative to a short-term JSA beneficiary. Given that the benefit officers had to achieve a quarterly target number of points, this incentivized them to focus on placing the IB claimants into jobs.

Consider a multi-tasking model with fixed inputs along the lines of Holmstrom and Milgrom (1991). Assume that the Jobcentre officers have a given stock of "inputs". They can apply different amounts of this "input" to different individual clients (benefit claimants). These inputs affect the outcomes experienced by claimants. In our context, the input variable represents staff time for interviews and the direct costs of the services provided. After the introduction of the explicit weighting system, we expect them to reallocate their efforts in favour of IB claimants, with adverse effects on JSA claimants' job finding prospects. ${ }^{12}$

\subsection{Identification}

We exploit the staggered roll-out of JCPlus offices across Local Authority Districts in the UK to

\footnotetext{
10 This included those with disabilities, participants in New Deal for Lone Parents, partners of continuously unemployed for 26 weeks, homeless people and qualifying ex-offenders.

${ }^{11}$ We discuss the other main group, Lone Parents (non-working single moms) in Section 6.

${ }^{12}$ Unfortunately, we are not able to measure staff inputs, but we can observe participant outcomes. So, in a sense this is a reduced form estimation.
} 
identify the causal impact of the policy. The switch to JCPlus was phased in over six waves, as illustrated in Figure 2. The figure shows the additional districts covered under each wave. The first wave begun on 1st October 2001 in 32 districts, the second wave began in October 2002 with 27 more districts, and by the first quarter of 2008, almost $100 \%$ of the country was covered. Figure 3 presents a map of the policy roll out, showing no obvious patterns of geographic clusters that adopted the policy at the same time.

We consider treatment as the "go live" quarter for a district. To address concerns that districts were not randomly assigned into treatment, in Section 4 we check for differences in pretrends between the treated and non-treated for various benefit categories.

There are multiple offices in a district (between 32 and 171), and we also considered exploiting within-district variation from the policy diffusion across offices. However, we found that although observables could not predict which districts were treated, there did appear to be a systematic component of which offices within a district were treated. For example, it is likely that a district treated the offices with a higher benefit outflow rate to begin first (Table A2). ${ }^{13}$ Further, the points system was formally set at the district level, so this seems a natural level of disaggregation.

We use a difference-in-differences framework to identify the causal impact of JCPlus. Since all districts are treated eventually, effectively we are comparing districts which are treated in a particular year and quarter to those who are treated at a later stage. Our main outcomes are the number of exits from disability and unemployment benefits in each quarter in each district. Since we also control for the lagged stock of claimants, the regressions can be considered as welfare outflow equations.

One potential concern is that jobseekers may be manipulating the benefit category that they apply to, thus affecting the composition of the claimant stock in each clients' group and the corresponding outflow rate from benefits. For instance, benefit applicants may have an incentive to enter the caseload under the IB rules rather than under JSA rules. However, being classified as eligible for IB requires a medical certificate, and conditions required to qualify have been made

\footnotetext{
${ }^{13}$ National Audit Office (2008) states that "Whilst an overall vision of the service improvements was successfully communicated from the centre, the detailed planning of the roll-out was delegated to the districts.... Implementation of Jobcentre Plus was a locally driven process" and that "Localised planning allowed Jobcentre Plus to make early progress with the roll-out, as the districts which were ready first could be scheduled for early roll-out".
} 
stricter over time, ${ }^{14}$ leaving limited leeway as to what kind of benefits one would be eligible for. A related concern is that the introduction of JCPlus may affect jobseekers' decisions whether to sign-on at all for benefits. To examine these concerns further, we also analyse the impact of JCPlus on the inflows into different benefit categories in Section 4.

\section{Data}

We use administrative data provided by the UK Department of Work and Pensions, covering the whole population on welfare. The JSA database contains monthly information from June 1983 on the stocks, inflows and outflows of unemployment benefits' recipients. The data is available at the Local Authority District level across Great Britain, with 406 districts. ${ }^{15}$ We further disaggregate claimants by age groups, 18-24 year olds, and 25-59 year olds. ${ }^{16}$

The second dataset contains quarterly data from 1999Q3 at the district level on other welfare benefits, among which the key disability benefit is IB. To be consistent across the two datasets, we aggregate the monthly JSA data at the quarterly level, but use monthly information as a robustness check. We estimate all our specifications on a consistent time period of nine years, from 1999Q3 to 2008Q2, the quarter before the collapse of Lehman's, which triggered the Great Recession and a huge upsurge of unemployment.

Descriptive statistics are presented in Table 1. Columns (1) and (2) refer to national aggregates per quarter, and columns (3) and (4) refer to (unweighted) averages across districts, age groups and quarters. The aggregate outflow rate from JSA is about $70 \%$ per quarter, and the gross outflow is slightly higher than the gross inflow, as unemployment was falling over the sample period. Outflow rates from IB are much lower at nearly 3\% per quarter. As expected, far

\footnotetext{
${ }^{14}$ For instance, in 1999, the Welfare Reform and Pensions Bill introduced 'continuing assessment of possibility of returning to work' (Burchardt, 1999). While the criteria for benefit receipt remained unaltered, the significant change was the collection of additional information focussing on the abilities of the claimant at intervals and the allocation of a personal adviser to oversee each claim. New claimants were also required to attend an interview at the beginning of the claim, and any time thereafter, to discuss possibilities for returning to work. More recently, applicants to IB will have to go to a Work Capability Assessment during the first 13 weeks of IB. This was aimed to see if the illness or disability affected the claimant's ability to work.

${ }^{15}$ Local government in England operates under either a single-tier system of unitary authorities and London boroughs, or a two-tier system of counties and district councils. The spatial units in our analysis include the unitary authorities, London boroughs and districts within counties. There are 352 such units in England. Local government in Scotland is organized through 32 unitary authorities. Since 1 April 1996, local government in Wales is organized through 22 single-tier principal areas. The Scottish and Welsh unit areas are also included in our sample.

${ }^{16}$ We have also considered an alternative age cut-off 25-54 for the older age group, and the empirical results were not affected.
} 
fewer people leave the stock of disability rolls than unemployment.

\subsection{Jobcentre Plus and Benefit Flows}

We estimate benefit outflow equations in a difference-in-differences framework. We first estimate a static model to estimate the average effect over time arising from JCPlus introduction. The specification is:

$$
\ln Y_{a i t}^{B}=\beta^{B} D_{i t}+\gamma_{1}^{B} \ln U_{a i t-1}^{B}+\gamma_{2}^{B} \ln U_{a r i t-1}^{B}+\delta_{a i}^{B}+\delta_{a t}^{B}+\varepsilon_{\text {ait }}^{B},
$$

where $Y_{\text {ait }}^{B}$ is the number of people in age group a leaving the benefit register $B$ (JSA or IB) in district $i$ at time $t$ (quarter). $D_{i t}$ denotes a treatment dummy which turns on in the quarter when the first office in district $i$ is treated. The coefficient is identified by the fact that the policy was rolled out in six waves with different districts being treated in each wave. One robustness test we consider is to allow $\beta^{B}$ being different in each wave and showing that the effect looks remarkably similar across waves when the post-wave window is kept fixed. As noted above, we found that the timing of when a district was treated appeared to be unrelated to observables.

We include as controls the stock of claimants of benefit $B$ at the end of the previous quarter for the own age group, $U_{\text {ait-1 }}^{B}$, as well as for the other age group, $U_{\text {ait-1 }}^{B}$ (old/young respectively). Our preferred specifications include a full set of fixed effects (district by age) and age by time dummies, but we also show more restrictive specifications just including separate district, age and time effects. We cluster the standard errors at the district level, which is the level at which the policy is defined, but results are robust to alternative ways of dealing with spatial autocorrelation (e.g. Conley, 1999).

In equation (1) the treatment effect is summarized by the coefficient $\beta^{B}$, which is an average over all the post-treatment quarters. The presence of adjustment costs, however, suggests that there should be a distinct dynamic pattern of change with the positive policy effects being dampened at first by organizational disruption. Hence, we allow the policy effect to be different depending on how many quarters have elapsed since the policy.

$$
\ln Y_{\text {ait }}^{B}=\sum_{\tau=1}^{7} \beta_{\tau}^{B} D_{i t+\tau}+\beta_{L R}^{B} D_{i L R}+\gamma_{1}^{B} \ln U_{a i t-1}^{B}+\gamma_{2}^{B} \ln U_{a \prime i t-1}^{B}+\delta_{a i}^{B}+\delta_{a t}^{B}+\varepsilon_{a i t}^{B} .
$$

The $D_{i t+\tau}$ term is broken down such that $D_{i 1}$ is the quarter in which the policy is turned on, $D_{i 2}$ is the first quarter after the policy is turned on, and so on. $D_{i L R}$ is the "long-run", defined as 8 quarters or more since the policy change. Since the last treatment wave is in 2006Q3, we have at 
least two years of post-policy experience for all districts. While ending the dynamics after two years is somewhat arbitrary, the treatment coefficients seem stable afterwards and we show that the qualitative results are robust to alternative dynamic specifications (e.g. Table A4)

The disruption hypothesis suggests $\beta_{1}^{B}<\beta_{2}^{B}<\beta_{3}^{B}$ and so on, implying that the initial negative disruption effects unwind as the new organizational structure settles down. The incentive hypothesis suggests that the positive effects on IB should be stronger than on JSA i.e. $\beta^{I B}>\beta^{J S A}$.

\section{Results}

In this section we present both the average impact of JCPlus on the outflow from benefits, as well as its dynamic evolution, and then turn to examining its effect on inflows into benefits.

\subsection{Basic Results on Outflows from benefits}

In column (1) of Table 2 we estimate equation (1) where the dependent variable is the (log of the) outflow from unemployment (JSA claimants). Our controls include the stock of unemployed claimants at the end of the previous quarter by age group, time (quarter by year), age and district dummies. The coefficient on the post-policy dummy is negative and significant, suggesting that a treated district, on average, experiences a 1.5\% decrease in unemployment outflows. Given an average unemployment outflow of about 650,000 per quarter, this implies just under 10,000 more people staying on unemployment benefits. This overall impact is consistent with both disruption effects and incentives for benefit officers to substitute effort away from the unemployed and towards the disabled. As expected, the lagged stock of own age unemployed claimants enters with a significant positive coefficient, while the stock of the other age group has a negative impact, suggesting job competition effects across age groups. In column (2), we include a full set of fixed effects (district by age dummies) and again find a significant negative coefficient on the post-policy variable. This result remains unchanged when we also include age interacted with time effects in column (3).

We repeat the same specifications in columns (4)-(6) of Table 2 for the (log) outflow from IB, and condition on the lagged IB stocks on the right hand side. In column (4) we estimate the specification analogous to column (1) and find a positive and weakly significant coefficient the post-policy dummy, suggesting a $1.7 \%$ increase in total outflows. Given a sample average 
outflow of 56,000 people, this means an additional 1,000 people off the IB register. In column (5), we include a full set of fixed effects and in column (6) we include age*time dummies. The treatment effect falls slightly to $1.5 \%$, roughly equal in absolute value to the policy coefficient in the unemployment outflow equation. ${ }^{17}$

The specifications in Table 2 just looks at the post-policy period as a whole without examining the dynamics of the policy effects. To assess short-run effects arising from organizational disruption, Table 3 probes the dynamics more carefully, allowing a differential effect in each of the quarters after the policy switches on (up to the eighth quarter after introduction) as in equation (2).

Interestingly, the coefficients show a consistent dynamic pattern, being negative in the quarter immediately after the policy introduction, but then becoming more positive over time. We detect negative impacts on JSA outflows for the first 5 quarters, but these cease to be significant by quarters 6 and 7 and actually turn positive for quarter 8 and beyond. This suggests that after two years there is a positive effect of $1.2 \%$ on outflows due to the policy, although this effect is not significantly different from zero. In contrast, for IB outflows, although we find a negative effect in the first quarter after the policy is introduced, this turns positive by the second quarter. This positive effect gradually becomes larger and more significant, and in the long-run it suggests $6.1 \%$ extra disabled people left the register in the most general specification of column (6).

These dynamic responses are presented graphically in Figure 4 and highlight our two main findings. First, the long-run effect is positive for both forms of welfare, but it is clearly much stronger for disability benefits (Panel B) than unemployment benefits (Panel A). Second, there is initially a negative effect for both benefits, but this is much stronger for unemployment than disability benefits.

The interpretation of our results is that the more positive long-run effect of the policy on disability compared to unemployment is driven by the new incentive system, such that officers devote more effort to helping the disabled into new jobs than the unemployed after the policy change. Overlaid on this, however, is an initial disruption effect as buildings and new systems bed down and a generally positive effect on both groups from improved information. This

\footnotetext{
${ }^{17}$ The results are robust to conditioning on stocks (by age group) of other benefit recipients (i.e. IB and lone parent stocks in JSA outflow equations, JSA and lone parent stocks in IB outflow equations).
} 
depresses all outflows and is an adjustment cost of the policy.

An alternative explanation would be that incentives do not matter but somehow the information treatment had a disproportionately larger effect on IB claimants than the unemployed. It is not obvious why this should be, but we will look at a more refined test of the incentives hypothesis involving a third group of welfare recipients (lone parents) where bureaucratic incentives are somewhere in-between those for the other two groups. We find results again consistent with the incentive hypothesis when looking at outflows from benefits for this third group (see Section 6).

\subsection{Pre-policy trends}

A threat to a causal interpretation of our estimates would be the existence of differential prepolicy trends. For example, if districts initially selected for treatment were those in which IB outflows were already increasing (and/or JSA outflows decreasing), we would estimate a positive (respectively, negative) impact of treatment even in the case in which the policy had no real effect. To investigate this we look at pre-treatment trends by estimating the following augmented specification of equation (1):

$$
\ln Y_{a i t}^{B}=\sum_{k=1}^{K} \beta_{k}^{B} D_{i t-k}+\beta^{B} D_{i t}+\gamma_{1}^{B} \ln U_{a i t-1}^{B}+\gamma_{2}^{B} \ln U_{a \prime i t-1}^{B}+\delta_{a i}^{B}+\delta_{a t}^{B}+\varepsilon_{a i t}^{B} .
$$

The first term on the right hand side of equation (3), $\sum_{k=1}^{K} \beta_{k}^{B} D_{i t-k}$, allows for pre-policy trends. The results are reported in Table 4. Column (1) replicates our baseline specification for JSA outflows (column (3) of Table 2) for comparison. In column (2) we include four pre-treatment lags and note that the coefficients on the pre-treatment dummies are jointly insignificant (F-test 1.88). We perform the same specifications for IB in columns (3) and (4) and again find no evidence of pre-treatment effects.

Although this is reassuring, one caveat is that the individual dummy for the quarter immediately prior to treatment is significant at the $10 \%$ level for JSA in column (2). This could be due to the fact that our treatment indicator is based on the true "go live" date of Jobcentre Plus and there is likely to be some organizational disruption in advance of that date, which could spill into the previous quarter. ${ }^{18}$ This would reduce the benefits of the policy for JSA, but since these

\footnotetext{
${ }^{18}$ National Audit Office (2008) states that "It introduces a radical shift from the former impersonal surroundings of
} 
are insignificantly positive in the long-run anyway, it makes no substantive difference.

\subsection{Inflow Rates}

Our analysis focuses on the intended Jobcentre Plus outcome to increase the outflow rates from benefits, but a possible side effect is that the inflow rate into benefits also changes as a consequence of the policy change. The resulting bias in the estimated policy effect is hard to sign. One would expect an upward bias in the estimated effect of the policy on the JSA outflow (and a downward bias for the IB outflow) if the dissuaded individuals were less motivated in their job search and more weakly attached to the labour force - and vice versa.

To examine this issue directly we analyse the impact of the Jobcentre Plus on inflows into JSA and IB. We estimate a specification similar to equation (1), using the inflow into each benefit category as the dependent variable instead of the outflow:

$$
\ln \left(I N F L O W_{\text {ait }}^{B}\right)=\sum_{\tau=0}^{4} \beta_{\tau}^{B} D_{i t+\tau}+\beta_{L R}^{B} D_{i L R}+\rho \ln P o p_{a i t}+\delta_{a i}^{B}+\delta_{a t}^{B}+\varepsilon_{a i t}^{B}
$$

In the outflow equation we controlled for the stock of existing benefit claimants, and the corresponding stock in the inflow equations is the age-specific population $\left(P o p_{\text {ait }}\right)$. Ideally, as inflows (mostly) consist of people flowing from employment to unemployment, one should control for local employment on the right-hand side. But in the absence of high-frequency employment data at the district level we use the population figures as a proxy. ${ }^{19}$

In column (1) of Table 5 we show that, on average, Jobcentre Plus had no significant effect on the inflows into JSA. Along similar lines, column (3) shows no evidence of significant average effects on inflows into IB benefits. However, when we look at the dynamic impact on inflows in columns (2) and (4), we find that the policy had initially a negative and significant impact on inflows into both benefits, although these become positive and insignificant in the long-run.

To address whether this could be a concern for our results because of changing selection, we repeat outflow regressions controlling for various lags of the corresponding inflows. The results are reported in Table 6, where all specifications include fixed effects for both district*age

the Jobcentre and Social Security offices to a modern retail-style environment and has a major impact on the way in which staff interact with customers and hence the quality of service provided."

${ }^{19}$ We assign the mid-year population estimate from www.nomisweb.com (taken on the $30^{\text {th }}$ of June each year) to all the quarters in the year. Using interpolated quarterly population estimates (from the mid-year estimates) does not change our results. 
and age*time interactions. ${ }^{20}$ Columns (1)-(3) refer to JSA outflows. Although the coefficients on the inflow variables, whether one or four lags, are positive and significant as one would expect (since more recent welfare recipients are more likely to leave), our main results are robust to their inclusion. To see this, in column (3) we report our baseline equation (2) on the same sample as column (2), as some observations are lost when we condition on lagged inflows. The long-run effects in columns (1) and (2) are almost identical to those in our baseline specification of column (3), and the dynamic effects only slightly muted by the inclusion of inflows. Columns (3)-(6) refer to IB outflows, and all coefficients measuring the impact of policy are both qualitatively and quantitatively similar across specifications. In particular, the long-run positive effect of the policy on IB is still significant and only falls slightly from 0.0547 (column (6)) to 0.0503 in column (5). Hence, despite some effects on inflows, any change in composition arising from this does not appear to substantially affect our results.

\subsection{Outflows to employment vs. other destinations}

The JSA (but not the IB) database allows us to disaggregate outflows into alternative destinations, and in particular to look at outflows into work separately from outflows into other states (such as different benefits, training, inactivity, etc.) The results of this analysis are reported in Table 7, where columns (1) and (2) refer to outflows into work, while columns (3) and (4) refer to other destinations. The broad pattern for either destination looks similar to the overall outflow results, although the estimated effects appear stronger especially in the short run when looking at outflows into work rather than other destinations.

Negative effects on JSA outflows into both work and non-work can be rationalized if one takes into account the "stick" (job search monitoring) and "carrot" (search effort assistance) components of the interactions between JSA claimants and dedicated staff at Job Centres. The change in the incentive structure implied that JSA claimants would receive less assistance with the job search process than before, thus lowering their job finding rates, at least in the short run. But insofar as poorer job search assistance also implied less frequent contact with JSA claimants, one may expect looser monitoring and fewer transitions off benefits due to sanctions or discouragement (see also Manning, 2008, and Petrongolo, 2009, for the effects of monitoring on the time spent on JSA benefits).

\footnotetext{
${ }^{20}$ In alternative specifications, we explicitly control for the duration composition of the stock of benefit claimants at the end of the previous quarter, and find that the baseline outflow results are robust.
} 
Another interesting point to be noted about columns (1) and (3) is that the congestion effect stemming from job competition by jobseekers from other age groups is clearly not present in the JSA outflow into other destinations, as the other age group could be competing for jobs in the labour market, but not for other destinations.

Overall, the results in both specifications in Table 7 are comparable to the earlier results on total outflow in Table 2. This reinforces the validity of using total outflow as our dependent variable to proxy for outflow to work.

\section{Cost-benefit evaluation}

For the purpose of our cost-benefit analysis we consider a policy simultaneously introduced throughout the country, as the staggered roll-out would not offer much general insight into costs and benefits of similar hypothetical policies in other contexts. We conduct two thought experiments. First, we assume away the transitional disruption costs and assume that the steady state is reached immediately upon JCPlus introduction. This gives an idea of the long-run welfare effect of the policy. Second, we explicitly incorporate the dynamic effects estimated in Figure 4 and illustrate how costs and benefits map out over the transition to the long-run steady state. This produces lower benefits because disruption effects cause an initial increase in the welfare rolls. With discounting, this will reduce the present value of the policy change because the losses - including the initial rise in welfare rolls and set-up costs - are front-loaded, whereas the long-run benefits are more heavily discounted.

Our cost-benefit calculations take into account (i) the savings in administration costs implied by the reorganization of the welfare system; (ii) the increase in output implied by the impact of the policy on job finding; (iii) the net exchequer savings which enter into welfare through a lower deadweight loss taxation (the rest simply being transfers); (iv) the sunk set-up costs. We abstract from the leisure gains and losses of those on welfare.

\subsection{Long-run Cost Benefit Analysis}

The results of the steady-state analysis are represented in Table 8. According to audit reports, the annual running costs post-policy were $£ 3.3$ bn (row 1), about $£ 238 \mathrm{~m}$ lower than pre-policy (row 3).

The steady-state impact of Jobcentre Plus on job creation is obtained from the long-run 
estimates reported in columns (3) and (6) of Table 3. Conservatively, we assume that the longrun policy impact on unemployment outflows is zero, as although the point estimate is positive (0.012), it is insignificantly different from zero. We set the long-term impact on IB exits at 0.061. Using this estimate, we obtain the implied steady-state fall in the IB rate (IB stock over population), according to a flow model of IB entry and exit, as shown in Appendix B. Not all of these exits would be into employment. Using the Labour Force Survey (LFS) quarterly panel data for 1998Q2-2002Q2 (pre-policy) we observe that 30\% of IB exists are to jobs, while 70\% of terminations transit into other benefits or out of the labour force. We also find that $71 \%$ of the exits to jobs are full-time while the rest are part-time. We assume that non-employment exits would be to other benefits with cost on average equivalent to IB. This implies that IB spells that do not terminate into employment do not contribute to either job creation or to benefit savings. This is a conservative estimate of policy benefits, as several IB exits will be to no welfare benefits at all.

We use wage outcomes as proxies for additional output created, and consider three possible cases for individuals finding employment after an IB spell: the national minimum wage, the observed mean wage for individuals ending an IB spell in the LFS, and the median wage in the overall wage distribution, obtained from the ASHE 1\% sample of taxpayers. The middle case seems the most realistic but the minimum wage and median wage scenarios provide useful lower and upper bounds, respectively. Columns (1) to (3) of Table 8 correspond to the three alternative wage outcomes considered. Row 4 reports weekly earnings for each wage outcome, and row 5 reports the increase in GDP obtained by combining wage levels with job creation resulting from IB exits. The overall GDP gains range between $£ 0.5$ bn and $£ 1.4$ bn per year.

Row 6 reports the net gain resulting from a reduced deadweight cost of taxation. This is set to $40 \%{ }^{21}$ of the lower net exchequer cost arising from increased tax revenues and lower benefit payments. The mean IB payment in 2000 was $£ 74.71$ per week. When an IB recipient finds a job, this benefit saving is accompanied by a change in the tax revenue that depends on the earnings and the household composition of the recipient. We used the IFS TAXBEN ${ }^{22}$ simulation model to approximate these additional taxes and benefits for the $30 \%$ of IB exits who found

\footnotetext{
${ }^{21}$ This follows Gruber (2011).

22 Estimates were provided by Barra Roantree of the Institute for Fiscal Studies using the IFS tax and benefit microsimulation model, TAXBEN.
} 
jobs. ${ }^{23}$ Combining these elements produces a benefit from a lower deadweight loss between $£ 110 \mathrm{~m}$ and $£ 200 \mathrm{~m}$.

The sum of the three components reported in rows 3,5 and 6 of Table 8 represents the total annual welfare impact of the policy in steady state. This implies an annual net benefit between $£ 1$ bn and $£ 2.2 \mathrm{bn}$ in 2010 prices (row 8). This benefit needs to be compared to the oneoff sunk set-up cost of $£ 2.3 \mathrm{bn}$ (row 10) as estimated by audit reports. It is clear that the policy covers the sunk costs of the programme easily even on conservative assumptions. If we use the $3.5 \%$ social discount rate used by the UK government (HM Treasury, 2003) our cost-benefit analysis implies a net benefit of Jobcentre Plus in excess of $£ 25 \mathrm{bn}$, even under the most conservative assumptions (row 11).

\subsection{Cost Benefit Analysis with transitional dynamics}

While the previous calculations ignore the transitional dynamics, we now consider the dynamic effects of policy for each quarter since the policy change, using the estimates from columns (3) and (6) of Table 3. In this case we cannot impose the steady-assumptions used to compute the steady-state rise in the number of jobs, as this would be equivalent to assuming that the JSA and the IB rates reach their steady state levels within a quarter. We thus simply obtain the out-ofsteady-state number of jobs created as the predicted change in the benefit outflow in the relevant quarter, net of job separations during that quarter. With labour market churning, some of the workers who find jobs separate in subsequent quarters. We estimate these flows from the (prepolicy) LFS panel. ${ }^{24}$ For individuals who were on JSA and found jobs $2.3 \%$ lost them in the next quarter, and for IB the figure was $0.5 \%{ }^{25}$

The three earnings scenarios, as well as the running costs, are the same as those considered for the steady state analysis of Table 8 . We maintain all other assumptions on job finding rates for IB recipients, and, for JSA recipients, we compute on the LFS that $70 \%$ of exits

\footnotetext{
${ }^{23}$ We consider two household types, a single adult and a couple with two dependent children, and obtain the associated tax payments. We assume that two thirds of IB exits are represented by single adults, while the remaining third is represented by members of couples with two children consistent with our estimates from the LFS 1998Q2$2002 \mathrm{Q} 2$.

${ }^{24}$ The job separation rate is obtained as the ratio of inflows into IB (JSA) to the employed population of working age.

${ }^{25}$ These quantitative results are very similar to an analytical approximation of the change in employment rates during the transition to a new steady state (see Appendix B2).
} 
were to jobs. $^{26}$

The evolution of costs and benefits over time is represented in Figure 7. The flat, solid line represents the set-up costs, while the three dashed lines represent cumulative benefits since the quarter in which the policy turns on, for the three different levels of earnings. Regardless of the earnings assumptions, flow social benefits eventually exceed the costs so although incorporating dynamics substantially dampens down the net benefits (by almost an order of magnitude), it does not reverse the earlier positive assessment of the program. The present value of the net benefit of the reform is about $£ 2.5$-3.8bn which outweighs the $£ 2.3 \mathrm{bn}$ sunk cost.

It is worth noting that in the baseline case (middle dashed line in Figure 7), it takes about six years after policy introduction for net benefits to exceed set-up costs. This is mainly because of declines in unemployment outflows during the first two years of the new regime. Only after six years are job entry gains sufficient to compensate both the initial job entry losses and the setup cost. Therefore, although this is a policy which clearly passes the cost-benefit test, a policy maker will not cover the costs of introduction for six years. Constitutionally, UK general elections have to be held at least once every five years and the average tenure of a minister is usually only two years. Thus a politician's discount rate would be much higher than the social discount rate, implying systematic under-investment (see e.g. Aghion et al, 2013). This is why major changes to welfare systems like this are so rare.

\section{Robustness and Extensions}

\subsection{Disaggregating the treatment effect by wave}

The policy roll out was introduced in six waves across the country, and our baseline estimates exploit variation from each wave for identification. An important issue is whether the effect of treatment is heterogeneous across different waves, and in particular a legitimate worry could be that the dynamic effects that we identify may be instead due to averaging over heterogeneous effects in earlier and later waves.

To investigate this we estimated equation (1) separately for each wave of the policy rollout. In order to avoid conflating the dynamics with wave effects we keep a fixed post-treatment

\footnotetext{
${ }^{26}$ For the benefit and tax simulation we assume that $70 \%$ of JSA exits who find jobs live alone, while $30 \%$ live in a couple with two children. For IB, about $67 \%$ of those who find jobs live alone, while $33 \%$ live in a couple with two children.
} 
window of one year. The results are reported in Table 9. Although the standard errors are larger as the number of observations is substantially reduced, the estimated treatment effect is remarkably stable across the different waves. Panel A refers to JSA outflows. Compared to the pooled effect we reported in Table 2 of -0.015 , wave-specific estimates range from -0.10 (wave 5) to -0.20 (wave 1), which is a reasonably tight bound. IB estimates in Panel B are generally higher (a range of 0.011 to 0.32 ) than the pooled estimate of 0.015 , suggesting, if anything, that we might be underestimating the positive effect of the programme using the parsimonious specification of equation (1).

We also considered alternative specifications such as restricting the comparison areas to those that had not been treated (Table A3), which lead to similar results.

\subsection{Lone Parents' Benefits}

Besides JSA and IB, lone parents (overwhelmingly single mothers) on income support are the third large category on welfare rolls. Table A1 shows that the points awarded to helping a lone parent into work are the same as for IB. Hence one may expect to see this group responding in similar ways to the policy as the IB group. However, the lone parents group was not subject to the same pressures to look for jobs as the other two groups, implying a weaker expected policy treatment. There were also a raft of other policies aimed at lone parents during the same time period, including a large increase in the generosity of in-work benefits (similar to EITC) and a voluntary job assistance programme ("New Deal for Lone Parents"). These changes may contaminate our tests.

In column (1) of Table 10 we estimate equation (1) for welfare outflows for lone parents and obtain an average decrease of about $1.3 \%$ after the policy, only slightly below the $1.5 \%$ for IB. However, when testing for the presence of pre-trends in column (2) based on the analogue of equation (3), we find that the joint F-test rejects the hypothesis of no pre-policy trends $(\mathrm{F}=3.894)$, whereas we did not find evidence of differential pre-treatment trends for the unemployed or disabled (Table 4). We attempt to control for these pre-trends by including district-specific trends in column (3) and the joint F-test for pre-trends is now insignificant. Similar to the unemployment and disability results, however, we do find a negative effect one quarter before treatment, consistent with the impact of organizational restructuring which impedes service delivery even before the true "go live" date. When pre-treatment dummies are dropped in 
column (4), the coefficient on the policy variable is -0.01 and insignificant. This value falls about half way between the IB and JSA effects. In column (5) we estimate a dynamic specification, and find an initial negative impact, which becomes positive by quarter 6 and is significantly positive in the long run. The long-run effect of $2.5 \%$ is smaller than the long-run IB effect of $6.1 \%$ but larger than the JSA effect of $1.2 \%$ (Figure 8).

Overall, the treatment effects on lone parents appear to lie between the effects of JSA and IB. Just like the other benefits there appears to be an initial negative effect which we interpret as an organizational disruption effect. However, in the long-run there is a positive improvement consistent with an improvement in incentives.

\subsection{Spillover Effects}

One potential concern is that, in common with standard difference in difference approaches, we do not look at the general equilibrium effects of the policy. For example, Crépon et al. (2013) find that there can be unintended negative externalities of active labour market policies as the higher outflows from one benefit group take jobs at the expense of others, especially in depressed labour markets. We examine this idea by looking at outflows in neighbours to treated districts using an augmented for of equation (1):

$$
\ln Y_{\text {ait }}^{B}=\beta^{B} D_{i t}+\mu^{B} N B R_{i t}+\gamma_{1}^{B} \ln U_{\text {ait }-1}^{B}+\gamma_{2}^{B} \ln U_{\text {a'it-1 }}^{B}+\delta_{a i}^{B}+\delta_{a t}^{B}+\varepsilon_{\text {ait }}^{B} .
$$

We capture spillovers using a dummy (NBR) that is unity in the quarter when a district's neighbours are treated and zero otherwise. The associated effect is captured by the parameter $\mu^{B}$ and is identified by the fact that different districts had their first neighbour treated in different quarters. We define neighbouring districts as those with centroids within $10 \mathrm{~km}$ of the centroid of the main district.

The results are shown in Table 11. The sample is now smaller for two reasons. First, estimates are now based on the first five waves only, since all neighbours are treated by the sixth wave. Second, some districts have neighbours whose centroid is further away than $10 \mathrm{~km}$. The baseline impacts on JSA and IB hold true even in this sample as seen in columns (1) and (3). In column (2), the coefficient on $N B R_{i t}$ is positive, consistent with spillovers as the unemployed find it easier to get jobs due to lower JSA outflows in the treated areas. The coefficient is statistically insignificant, however. Similarly, in column (4), the coefficient on $N B R_{i t}$ is positive but insignificant. 
We investigated a range of alternative specifications, using other bandwidths for defining neighbours, including the proportion of treated neighbours rather than a discrete dummy for any neighbour treated, weighting by distance, interacting the policy and spillover effects with measures of labor market tightness (using vacancy rates), and interacting the policy effects with lagged stocks of benefit claimants. In no case could we find evidence that the policy had significant effects on other groups.

\subsection{Other Robustness Tests}

We have subjected our results to several other robustness tests, some of which we note here.

Other programmes. A concern with our design is that our estimated treatment effects may be potentially confounded by other policies implemented at the same time. The only other important policy targeted at IB claimants we could find was the "Pathways to Work" programme, which aimed to help claimants better understand and manage their health conditions and thereby improve their work prospects. It was originally introduced in October 2003 in eight pilot areas, and rolled-out to 14 expansion areas from October $2005 .{ }^{27}$ When including posttreatment dummies for the areas affected our baseline estimates are virtually unchanged. For example, using the specification of columns (3) and (6) in Table 2, the estimated long-term impact of JCPlus on JSA outflows changes from a coefficient (standard error ) of -0.0152 $(0.0055)$ to $-0.0147(0.055)$, and the estimated long-term impact on IB outflows goes from 0.0151 (0.0089) to $0.0149(0.0087)$.

Alternative dynamic specifications. We explored alternative dynamic specifications in Table A4, which confirmed the robustness of our main specifications.

Weighting. To address the concern that our results may be driven by a few small districts, we weigh observations by the district-level, age-specific benefit caseload in a pre-policy period (1999Q3). Table A5 reports the results for equation (1) using this weighting system. Column (1) has a treatment coefficient for JSA outflows of $2.5 \%$. Dynamic effects reported in column (2) are instead very similar to those of Table 3. For IB, the average effect reported in column (3) is lower than in the unweighted regression. The short and long run effects of the treatment are

\footnotetext{
${ }^{27}$ See Becker et al. (2010). Pilot areas were Bridgend, Gateshead, Somerset, East Lancashire, Essex, Derbyshire and Renfrewshire, Inverclyde, Argyll and Bute. The expansion occurred in three phases: phase 1 from October 2005 (covering Tees Valley, Cumbria, Lancashire West and Glasgow), phase 2 from April 2006 (covering Barnsley, Doncaster \& Rotherham, City of Sunderland, County Durham, Lanarkshire \& East Dunbartonshire, Liverpool \& Wirral, Greater Manchester Central and South West Wales; and phase 3 from October 2006 (covering Eastern Valleys, Greater Mersey and Staffordshire).
} 
however very similar to those from the unweighted regression.

Estimates at Monthly Frequency. We are able to estimate JSA (but not IB) outflow equations at the monthly, rather than quarterly, frequency. The dependent variable is now the monthly outflow from JSA, having included the stock at the end of the previous month as a control. Column (1) in Table A6 shows a policy coefficient unemployment outflows of $-1.6 \%$, which is very close to the baseline $-1.5 \%$. The dynamic results in column (2) are also similar to the baseline.

Heterogeneous Policy Effects. We investigated whether the treatment effects were heterogeneous in interesting ways across different groups. In particular we looked at whether the coefficients in columns (3) and (6) of Table 3 differed for welfare recipients of different ages, benefit durations, regions (e.g. London vs. others), and so on. We did not find evidence for much systematic heterogeneity across these groups.

\section{Conclusions}

The UK embarked on a major change in the administration of welfare benefits for the unemployed and the disabled in 2001 with the introduction of Jobcentre Plus. Bureaucratic incentives to help the disabled into jobs were sharpened, and offices were re-organised to be more efficient. At the same time, the growth of the stock of Incapacity Benefit recipients, which had been rising for 30 years, stopped increasing. We evaluate this policy in the light of a framework with incentives, information and adjustment costs. We show that there are potentially two unintended consequences of the policy change. First, the relative incentives to help the unemployed into jobs fell. Second, the re-organization of the job centres temporarily reduced outflow rates from benefits, likely due to disruption effects.

We found several results that are consistent with the existence of incentive and organization effects. First, we detect an increase in the outflow rates of both the groups of disabled and unemployed in the long-run, but the effects are much larger and only significant for the disabled. Second, there is evidence of important disruption effects, with outflow rates initially falling after the policy change for both groups.

A dynamic cost-benefit analysis of the policy suggests that the short-run costs are easily outweighed by long-run benefits. However, the benefits of the program take time to be visible 
and this poses a problem for policy-makers whose time horizons may be much shorter than that of a social planner. This highlights the political economy problem at the heart of welfare reform: changes to the administration of the benefit system that have long-run benefits may have significant short-run costs, and this makes it hard to build up a coalition for change.

There are many directions that the work could be taken. To what extent does the increased labour supply lead to lower equilibrium wages (not just due to compositional changes)? Can we unbundle further some of the elements of the policy to distinguish incentives effects from information (which conceivably could be more important for the disabled)? Could similar reforms be effective in other countries that have also seen large increases in the disability rolls? These are areas that we are currently pursuing.

\section{References}

Aghion, Philippe, Tim Besley, John Browne, Francesco Caselli, Richard Lambert, Rachel Lomax, Nick Stern and John Van Reenen (2013) Investing for Prosperity: Report of the LSE Growth Commission, LSE: London.

Autor, David (2012) "The Unsustainable Rise of the Disability Rolls in the United States: Causes, Consequences and Policy Options", Brookings Papers.

Autor, David and Mark Duggan (2003) "The rise of disability rolls and the decline in unemployment" Quarterly Journal of Economics 188(1), 157-206.

Banks, James, Richard Blundell and Carl Emmerson (2015) "Disability Benefit Receipt and Reform: Reconciling Trends in the United Kingdom", UCL mimeo

Bagaria, Nitika, Novella Bottini and Miguel Coelho (2013), "Human Capital and Economic Growth: A Focus on Primary and Secondary Education in the UK", LSE Growth Commission Report.

Barnes Martin and Richard Poynter (1997), Jobseeker's Allowance Handbook, Child Poverty Action Group, London.

Beatty, Christina and Steve Fothergill (2009), "Incapacity Benefits in the UK: An Issue of Health or Jobs?" Sheffield Hallam University mimeo.

Becker, Elizabeth, Oliver Hayllar and Martin Wood (2010) "Pathways to Work: programme engagement and work patterns", DWP Research Report 653

Besley, Tim and Maitreesh Ghatak (2005), "Competition and Incentives with Motivated Agents", American Economic Review 95(3): 616-636.

Bloom, Nicholas and John Van Reenen (2011), "Human Resource Management and Productivity", Handbook of Labor Economics Volume 4B in Orley Ashenfelter and David Card (eds), Chapter 19 1697-1769. 
Blundell, Richard, Monica Costa Dias, Costas Meghir and John Van Reenen (2004), "Evaluating the Employment Impact of a mandatory job search assistance programme", Journal of the European Economics Association, 2(4): 569-606.

Blundell, Richard, Claire Crawford and Wenchao Jin (2014), "Employment Composition, Hourly Wages and the Productivity Puzzle", Economic Journal, 124 (524), 377-407

Burchardt, Tania (1999), "The Evolution of Disability Benefits in the UK: Re-weighting the basket", mimeo.

Conley, Timothy G. 1999. "GMM Estimation with Cross Sectional Dependence." Journal of Econometrics, 92(1): 1-45.

Crepon, Bruno, Esther Duflo, Marc Gurgand, Roland Rathelot and Philippe Zamora (2013), "Do Labour Market Policies have Displacement effects? Evidence from a clustered randomized experiment", Quarterly Journal of Economics, 128 (2): 531-380.

Delong, Brad and Larry Summers (2012), "Fiscal Policy in a Depressed Economy" Brookings Papers on Economic Activity, Spring, 233-274.

Dolton, Peter and Denise O'Neill (1996), "Unemployment Duration and the Restart Effect: Some Experimental Evidence", Economic Journal, 106: 387-400.

Dolton, Peter and Denise O'Neill (2002), "The Long-Run Effects of Unemployment Monitoring and Work-Search Programs: Experimental Evidence from the United Kingdom", Journal of Labor Economics, 20, 381-403.

Gregg, Paul, Stephen Machin and Maina Salgade (2014), "Real Wages and Unemployment in the Big Squeeze", Economic Journal, 124(524) 408-432

Gregg, Paul (2009), "Welfare Reform and Lone Parents in the UK", Economic Journal, 119:F38-F65.

Gruber, Jonathan (2011), "Public Finance and Public Policy", Worth Publishers.

Heckman, James, Carolyn J. Heinrich, Pascal Courty, Gerald Marschke, and Jeffrey Smith (2011), "The Performance of Performance Standards", Upjohn Institute.

HM Treasury (2004) "Opportunity for all: The strength to take the long-term decisions for Britain”, Pre-Budget Report, London: HMSO.

HM Treasury (2003) "The Green Book: Appraisal and evaluation in Central Government", London: HMSO.

Holmström, Bengt and Paul Milgrom (1991), "Multitask Principal-Agent Analyses: Incentive Contracts, Asset Ownership, and Job Design", Journal of Law, Economics, and Organization 7(0): 24-52.

Hyde, Mark, John Dixon and Melanie Joyner (2002), "Work for Those Who Can and Security for Those Who Cannot: The United Kingdom's New Social Security Reform Agenda", International Social Security Review, 52(4): 69-86.

Johnson, Terry R. and Daniel H. Klepinger (1994), "Experimental Evidence on Unemployment Insurance Work-Search Policies", Journal of Human Resources, 29: 695-717.

Lalive, Rafael, Jan van Ours and Josef Zweimüller (2007), "How Changes in Financial Incentives Affect the Duration of Unemployment", Review of Economic Studies, 73: 1008-1038. 
Layard, Richard (2000), "Welfare to Work and the New Deal", The Business Economist $31,3,28-40$.

Manning, Alan (2009), "You Can't Always get What You Want: The Impact of the UK Jobseeker's Allowance”, Labour Economics, 16: 239-250.

Makinson, John (2000), "Incentives for Change: Rewarding Performance in National Government Networks", Public Services Productivity Panel, HMT.

Meyer, Bruce (1995), "Lessons from the U.S. Unemployment Insurance Experiments", Journal of Economic Literature, 33: 91-131.

Mueller, Andreas I., Jesse Rothstein and Till M. von Wachter (2013), "Unemployment Insurance and Disability Insurance in the Great Recession", NBER Working Paper no. 19672.

National Audit Office (2008), "The roll-out of the Jobcentre Plus Office network", London: HMSO.

Office for National Statistics, 2011 Census: Digitised Boundary Data (England and Wales), UK Data Service Census Support. Downloaded from: http://edina.ac.uk/census.

Pessoa, Joao and John Van Reenen (2013), "The UK Productivity and Jobs Puzzle: Does the Answer Lie in Labour Market Flexibility?" Economic Journal, 124, 433-452

Petrongolo, Barbara (2009), "What Are the Long-Term Effects of UI? Evidence from the UK JSA Reform", Journal of Public Economics, 93: 1234-1253.

Propper, Carol and Deborah Wilson, (2003), "The Use and Usefulness of Performance Measures in the Public Sector", CMPO Working Paper 03/073.

Riley, Rebecca, Helen Bewley, Simon Kirby, Ana Rincon-Aznar and Anitha George (2011), The introduction of Jobcentre Plus: An evaluation of labour market impacts, DWP Research Report No 9781.

Van Reenen, John (2004) "Active Labour Market Policies and the British New Deal for Youth in Context" in Blundell, R., Card, D. and Freeman, R. Seeking a Premier Economy. 
Figure 1: Number of disability Claimants (Incapacity Benefit) of working age: 1963 -2009

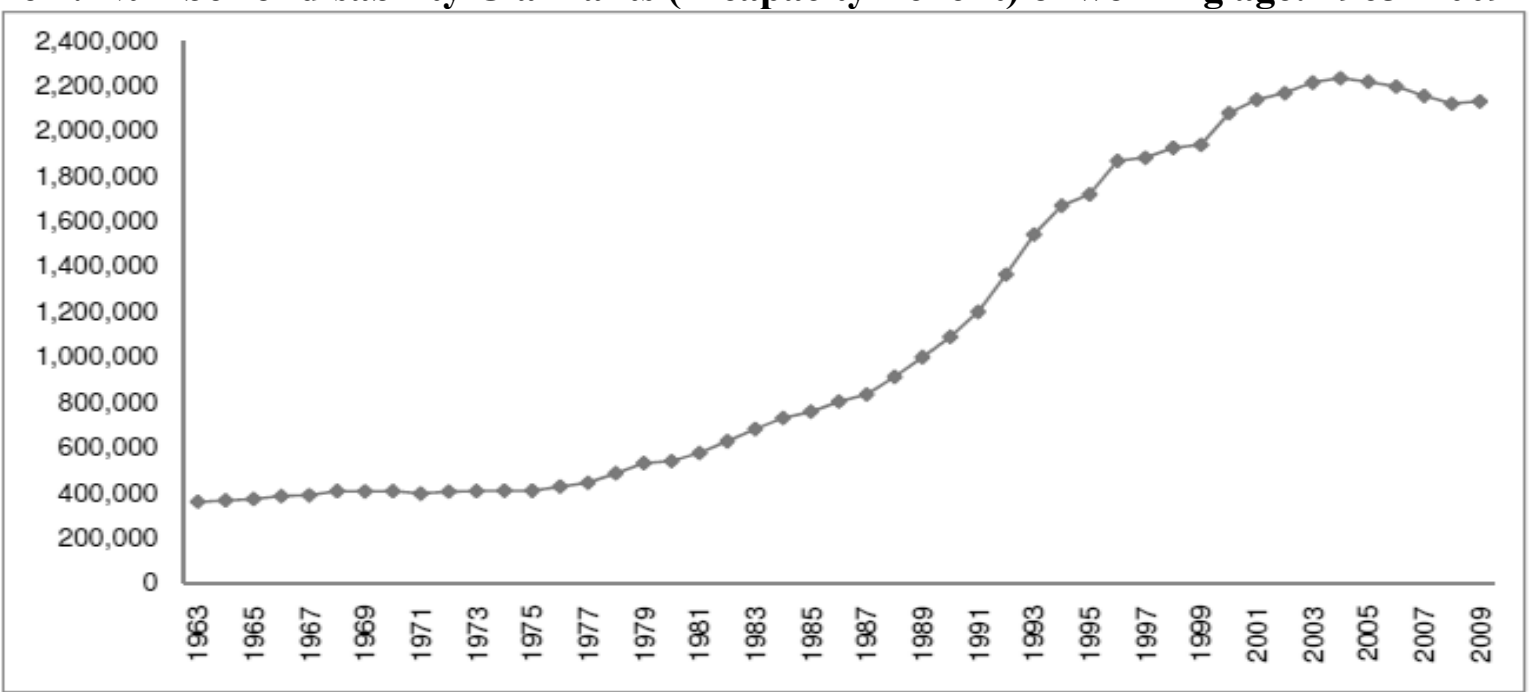

Source: Beatty and Fothergill (2009).

Figure 2: The Staggered Roll-out of the "Jobcentre Plus" Policy

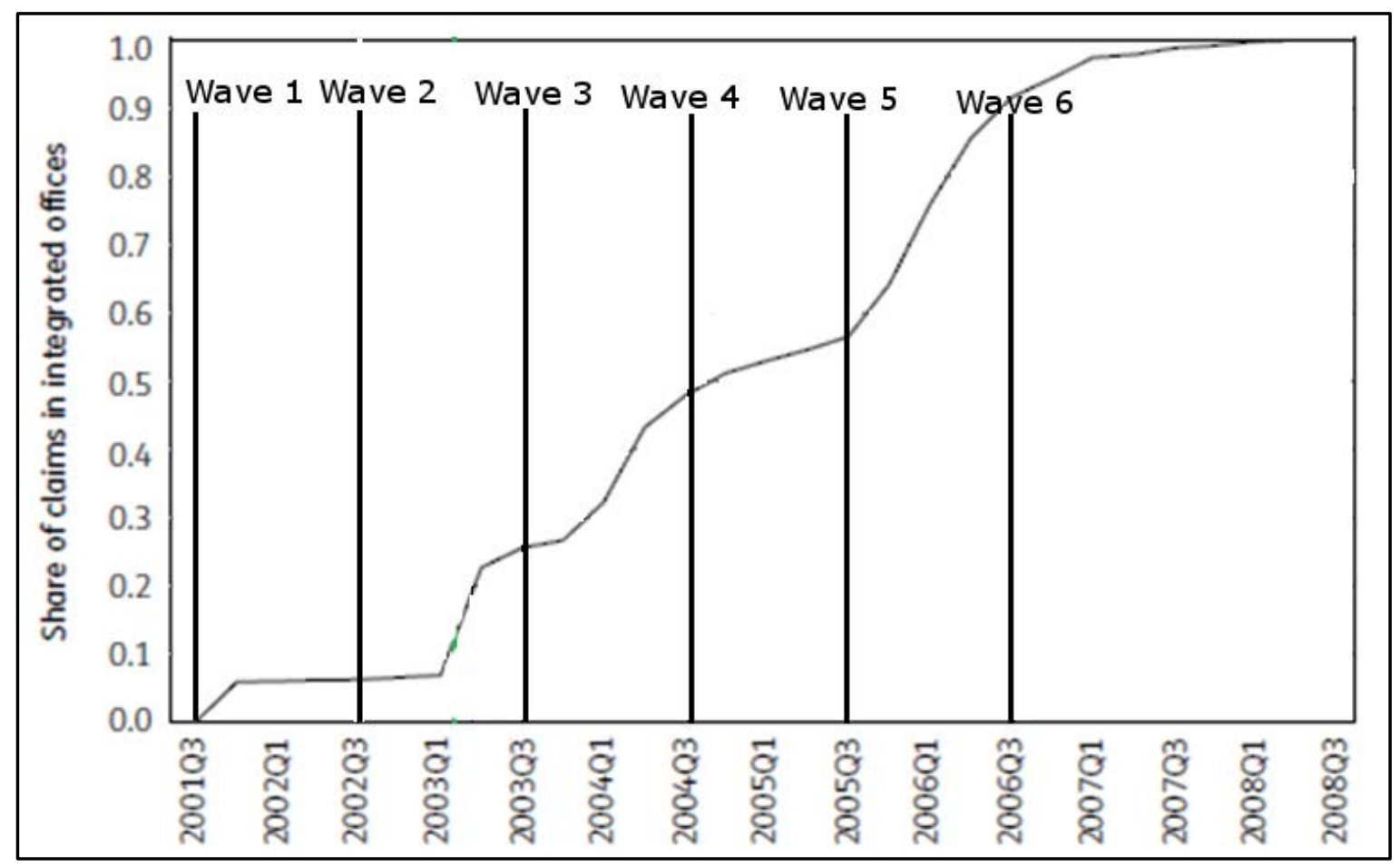

Notes: The vertical lines indicate the six waves of the roll-out of the policy (at the start of each wave at least one office switched to the new regime in a district). In Wave 1 there were 32 districts, in Wave 2 there were 27 districts, in Wave 3 there were 36 districts, in Wave 4 there were 28 districts, in Wave 5 there were 135 districts and in Wave 6 there were 148 districts. The line shows the proportion of JSA claimants who were affected by the policy (i.e. each office is weighted by the stock of JSA claimants in the quarter that the policy was turned on. Source: Riley et al (2011) 
Figure 3

Spatial Map of Diffusion, by Wave

Wave 1

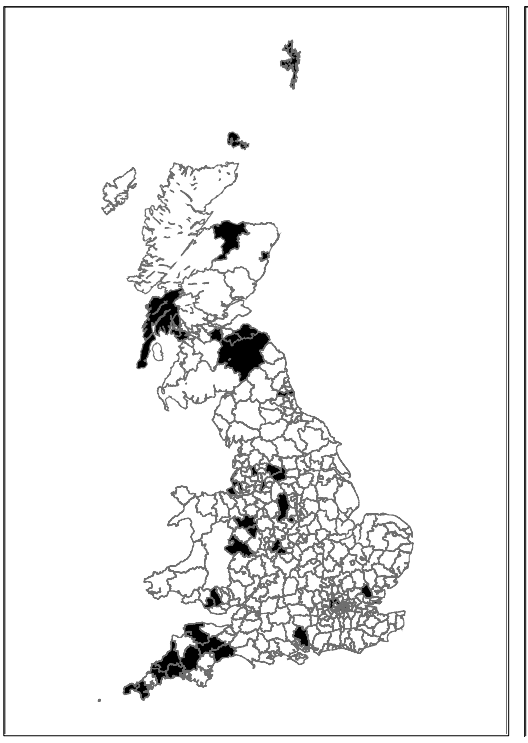

Wave 4
Wave 2

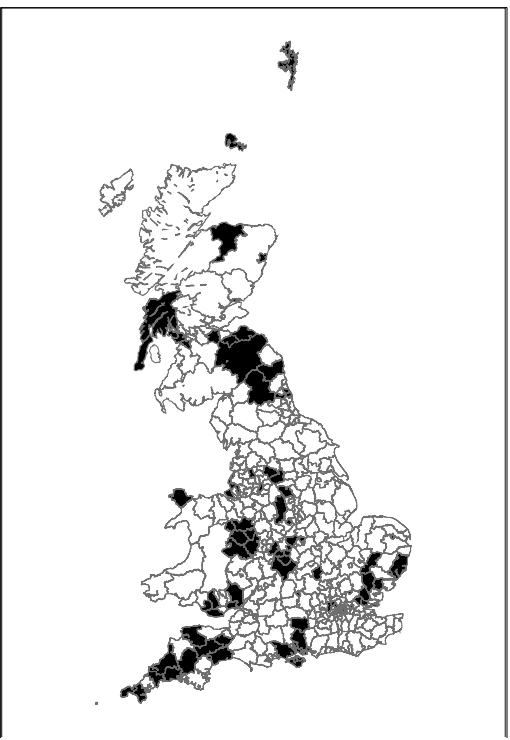

Wave 5
Wave 3

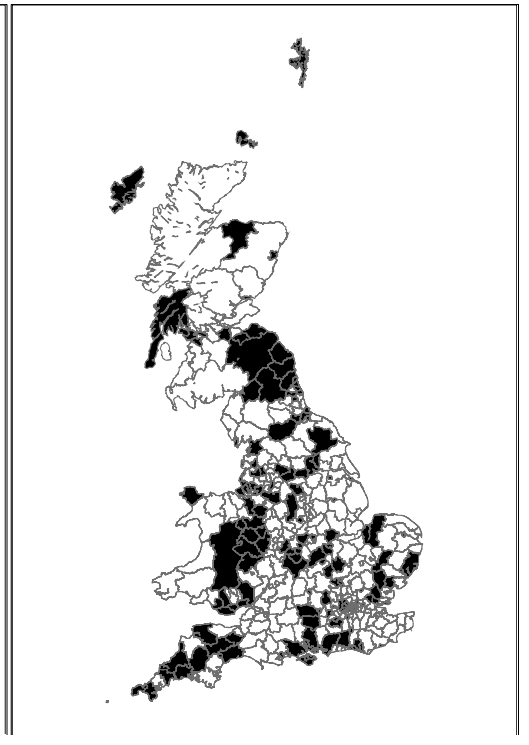

Wave 6

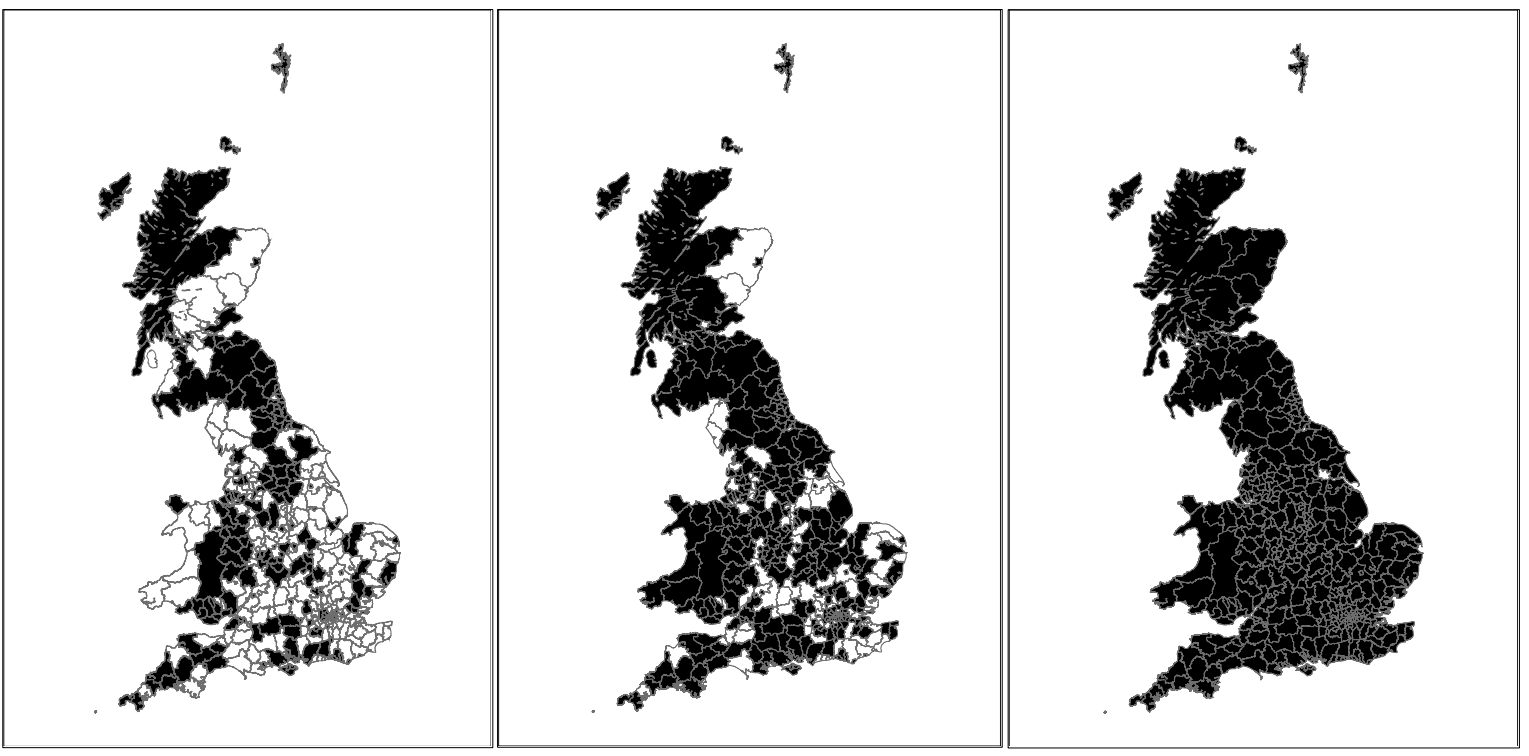

Notes: The maps show the additional districts covered under each wave. The treated districts are shaded in black. The first wave begun on 1st October 2001. In Wave 1 there were 32 districts, in Wave 2 there were 27 districts, in Wave 3 there were 36 districts, in Wave 4 there were 28 districts, in Wave 5 there were 135 districts and in Wave 6 there were 148 districts. By the first quarter of 2008 , almost $100 \%$ of the country was covered. 
Figure 4 Panel A: Dynamic Effects on JSA Outflow

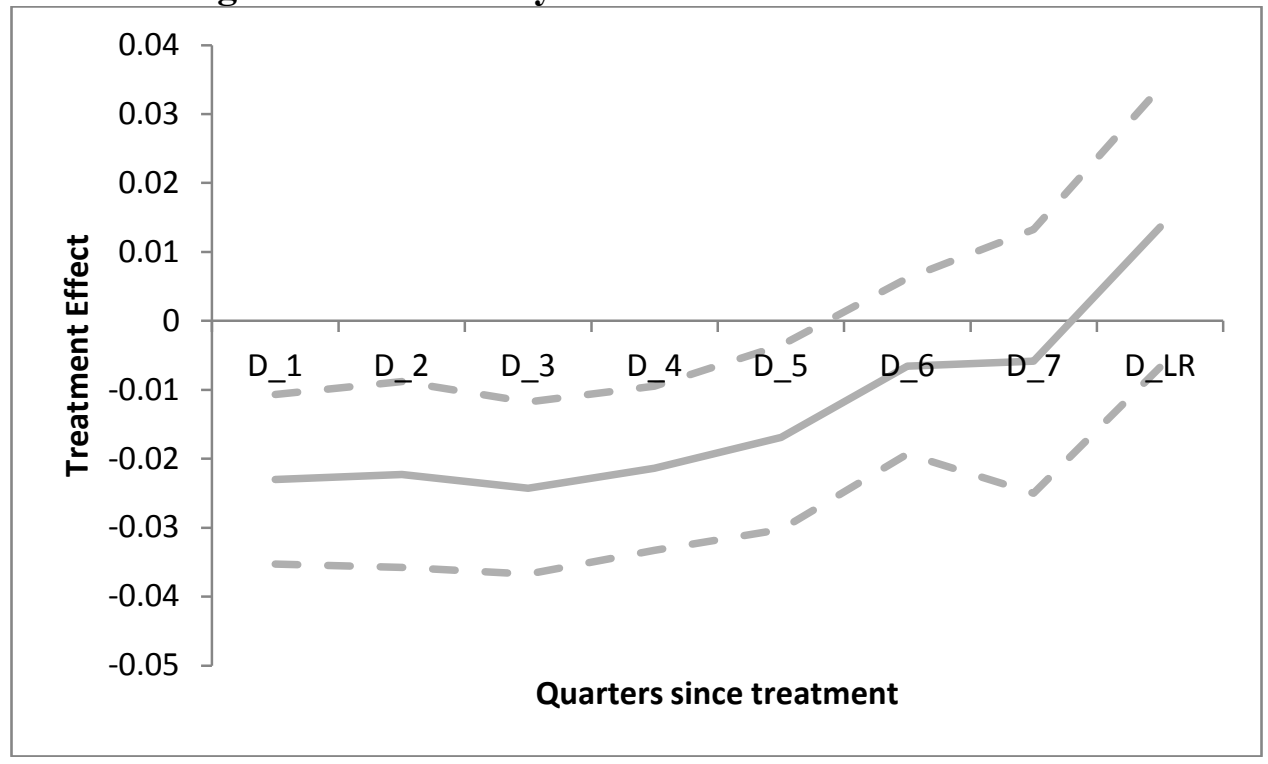

Notes: The sample is a panel of 406 districts from 1999Q3 to 2008Q2. The outcome variable (on y-axis) is ln (outflow) for JSA. The solid middle line denotes the estimated coefficients for the dynamic specification in equation (2) based on column (3) of Table 3. "D_1" indicated the effect of the policy in the first quarter after the go live date; "D_2", the second quarter and so on. "D_LR" is the long-run effect (after 8 quarters). The top and bottom lines denote the $95 \%$ confidence intervals.

\section{Figure 4 Panel B: Dynamic Effects on IB Outflow}

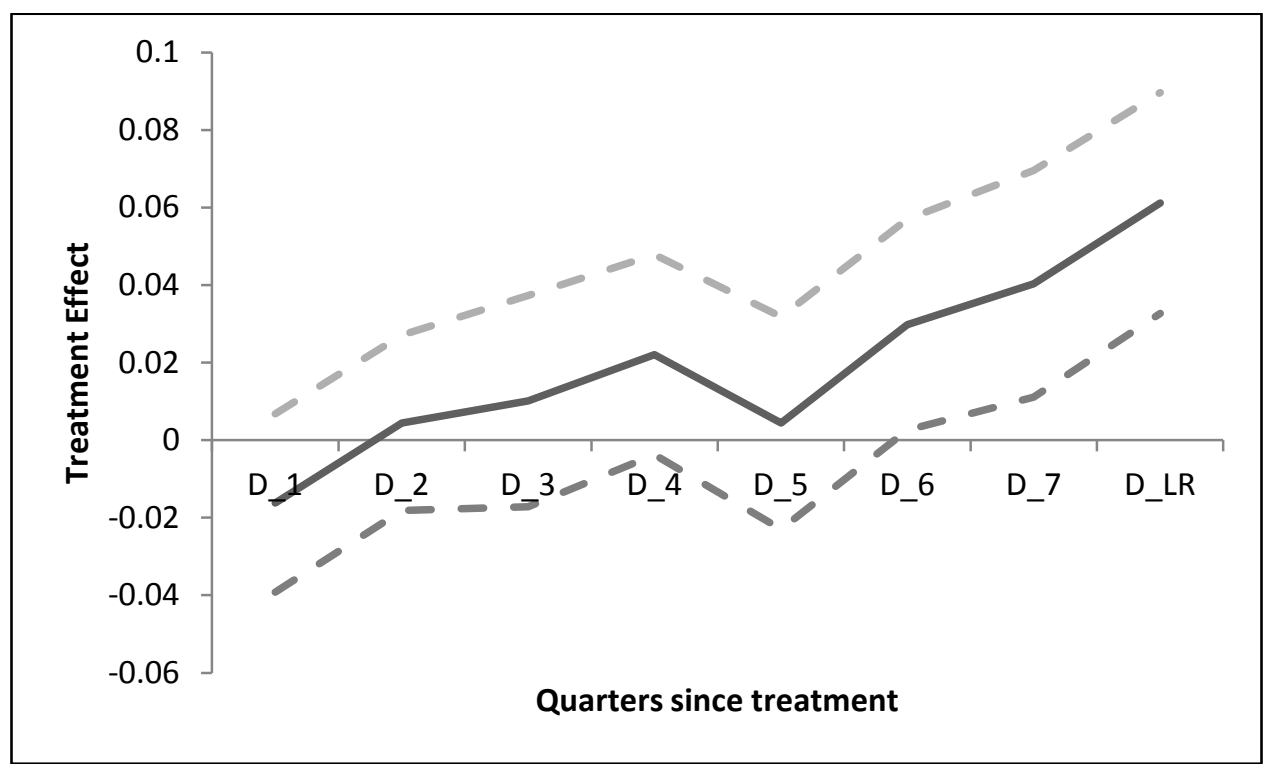

Notes: The sample is a panel of 406 districts from 1999Q3 to 2008Q2. The dependent variable is ln (outflow) for IB. The solid middle line denotes the estimated coefficients for the dynamic specification in equation (2) based on column (6) of Table 3. "D_1" indicated the effect of the policy in the first quarter after the go live date; "D_2", the second quarter and so on. "D_LR" is the long-run effect (after 8 quarters). The top and bottom lines denote the $95 \%$ confidence intervals. 
Figure 5: Dynamic Effects on JSA Outflows, with and without JSA inflow controls

A: No controls for JSA Inflows

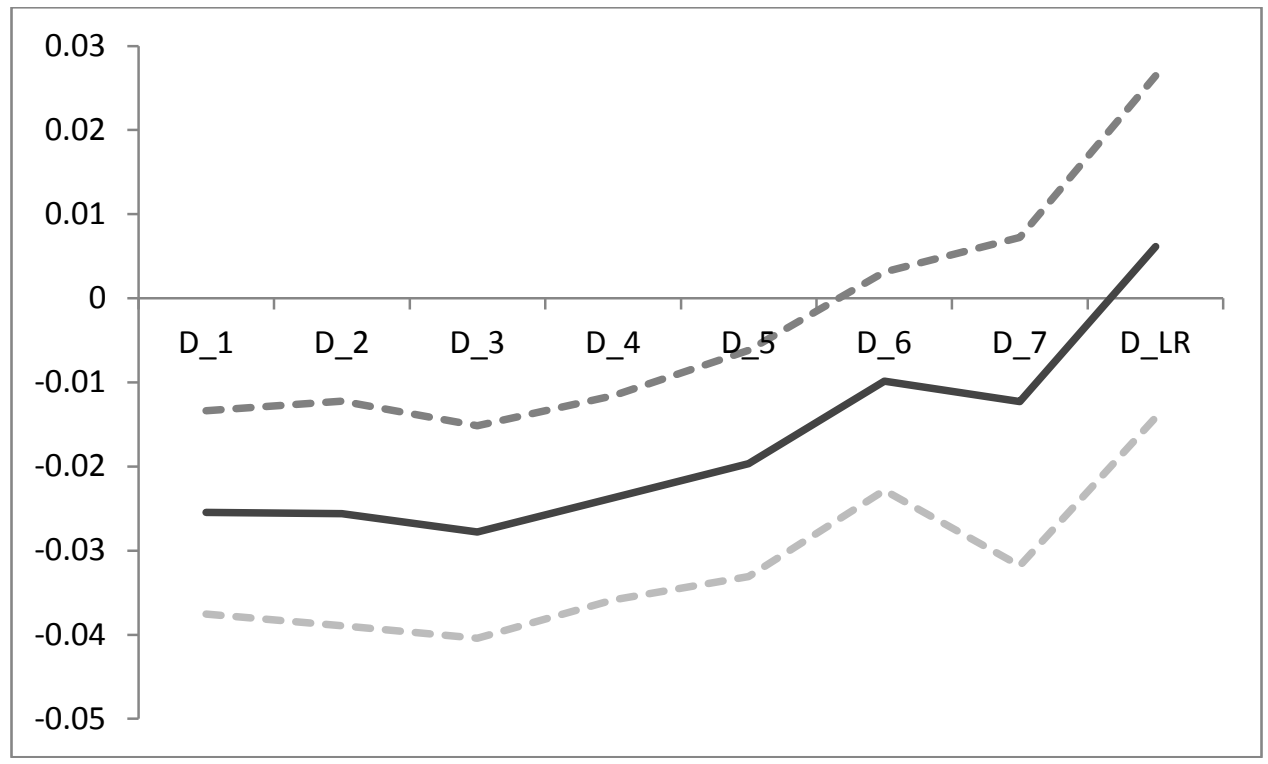

\section{B: Controlling for a fourth order distributed lag of JSA Inflows}

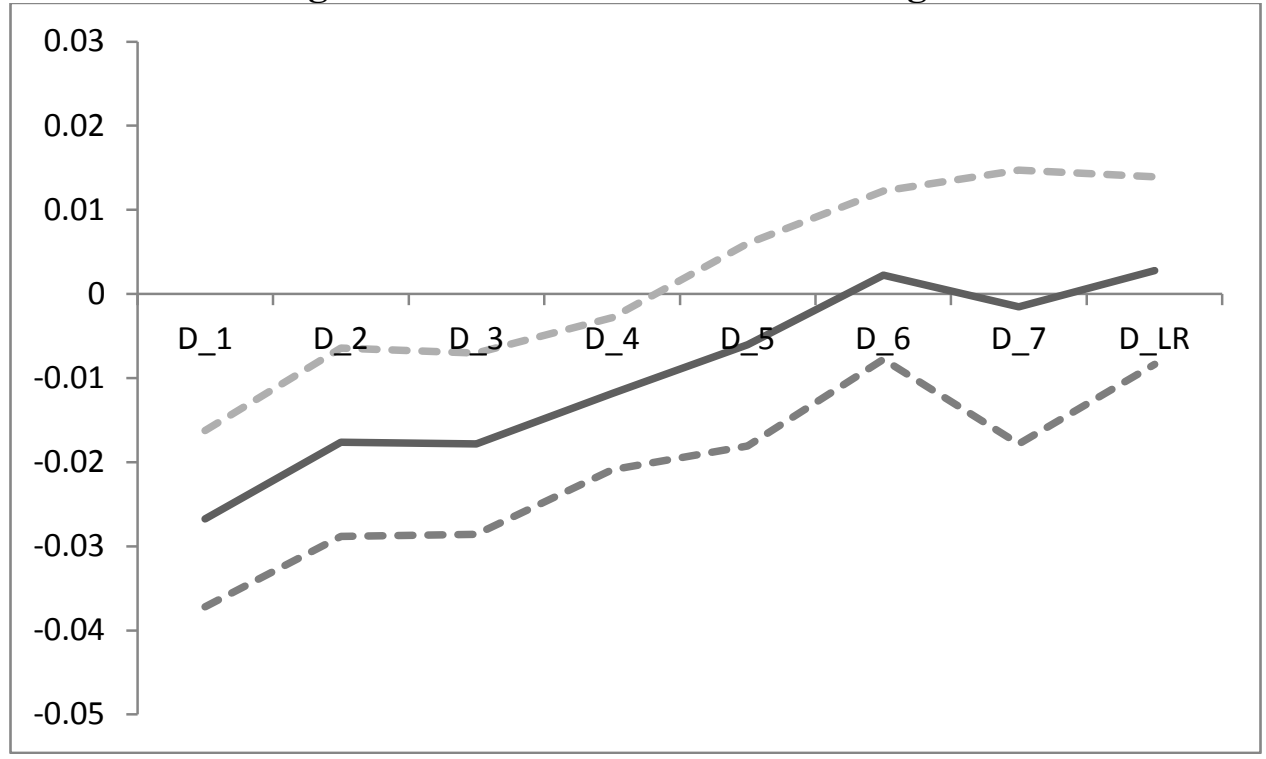

Notes: These are the coefficients in Table 6 column (2) and column (3). The dependent variable is $\ln$ (outflow) for JSA. The solid middle line denotes the estimated coefficients: "D_1" indicated the effect of the policy in the first quarter after the go live date; "D_2", the second quarter and so on. "D_LR" is the long-run effect (after 8 quarters). The top and bottom dashed lines denote the $95 \%$ confidence intervals. 
Figure 6: Dynamic Effects on IB Outflows, with and without IB inflow controls

\section{Figure A: No controls for IB Inflows}

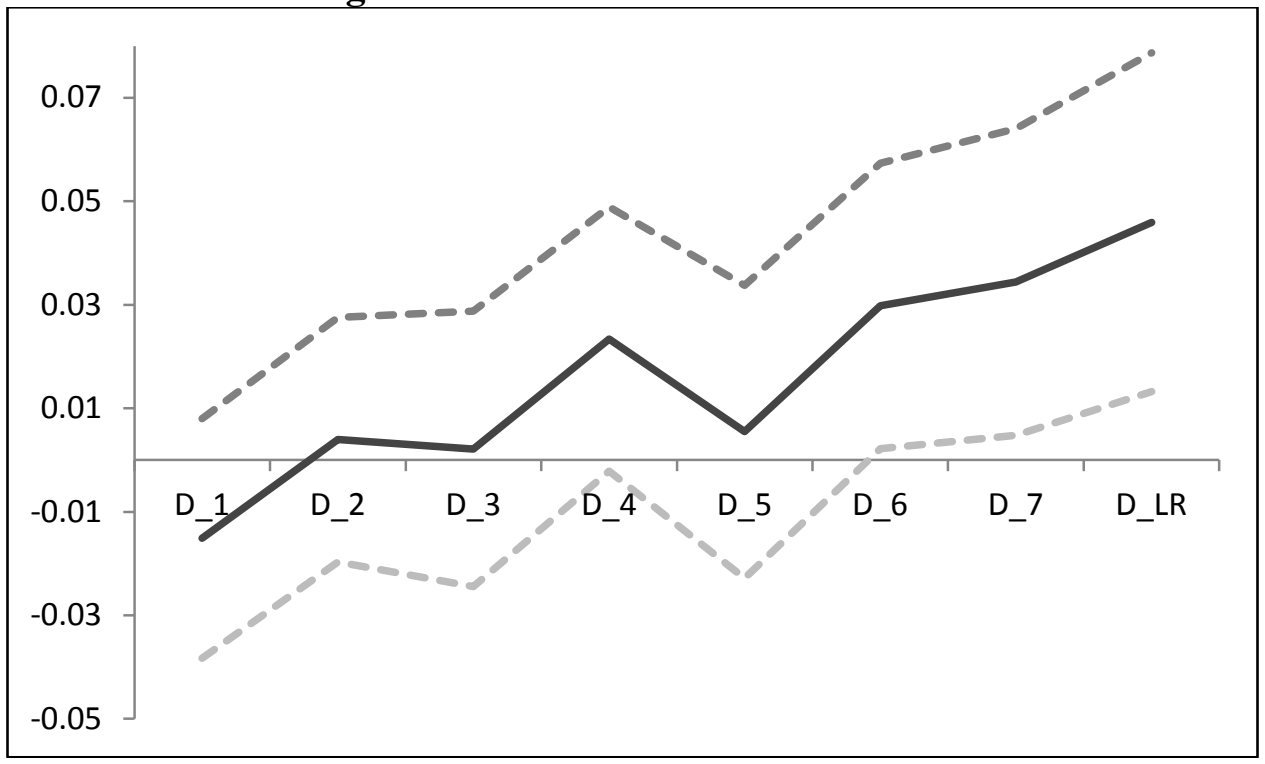

\section{Figure B: Controlling for a fourth order distributed lag of IB Inflows}

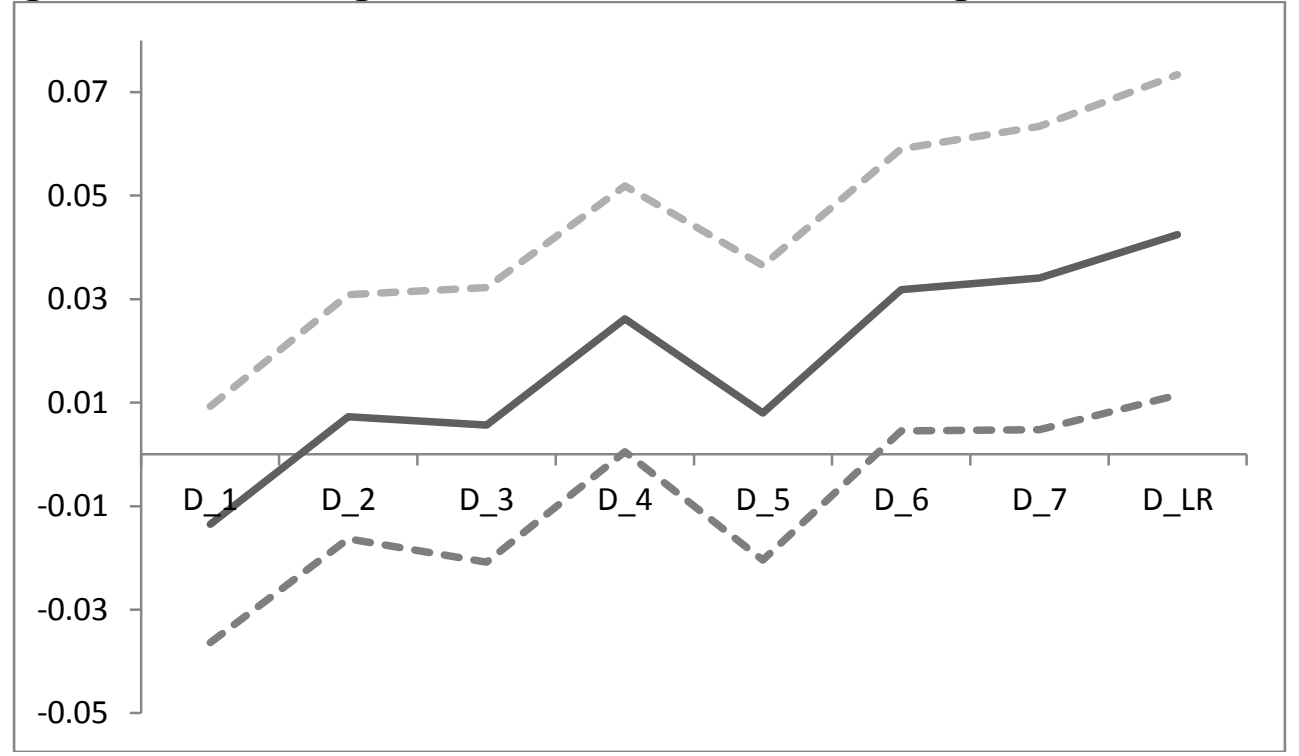

Notes: These are the coefficients in Table 6 column (5) and column (6). The dependent variable is $\ln$ (outflow) for IB. The middle line denotes the estimated coefficients and the top and bottom dashed lines denote the $95 \%$ confidence intervals. "D_1" indicated the effect of the policy in the first quarter after the go live date; "D_2", the second quarter and so on. "D_LR" is the long-run effect (after 8 quarters). 
Figure 7: Cost-benefit analysis of Jobcentre Plus: Dynamic evaluation

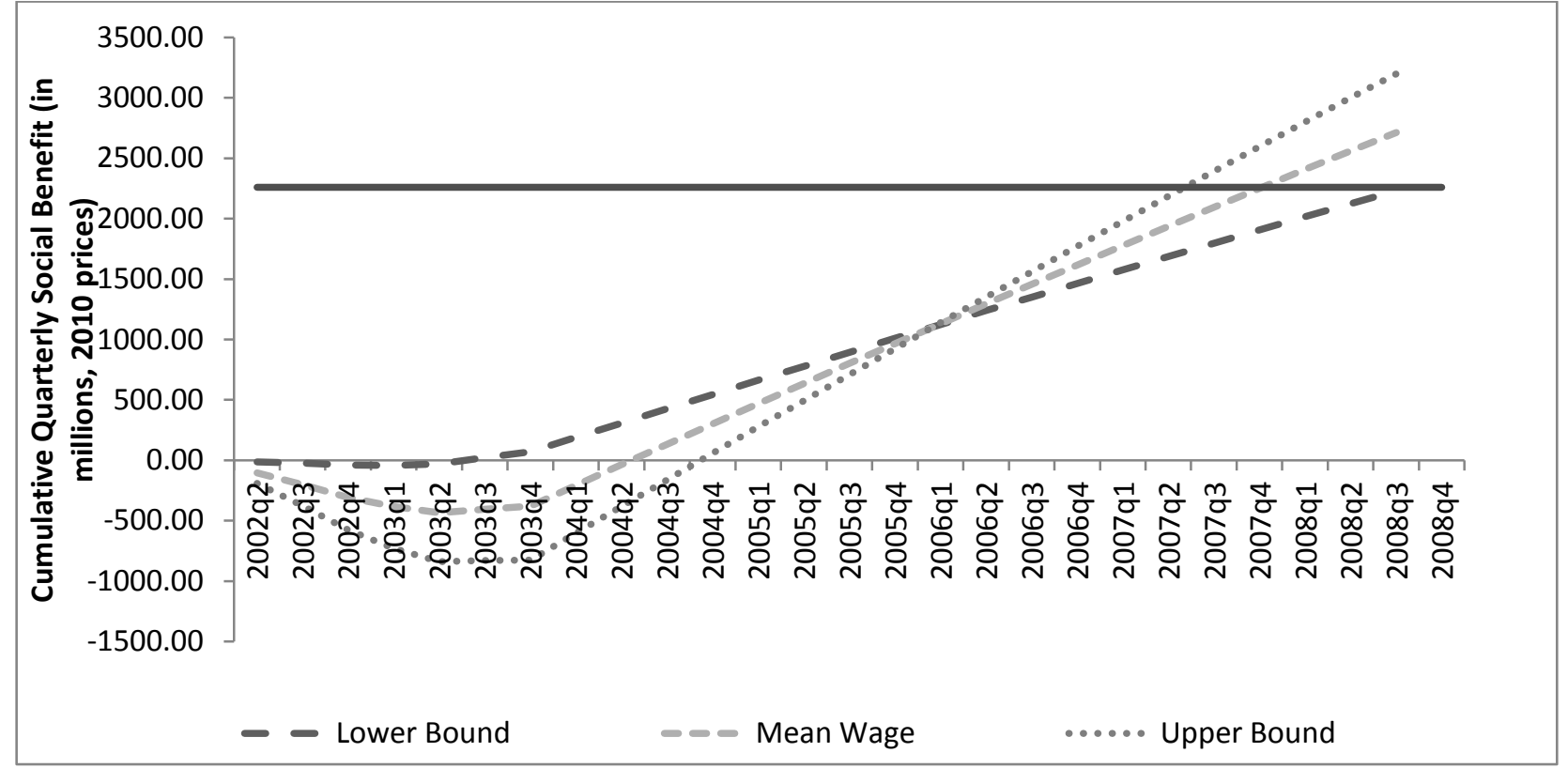

Notes: We consider an immediate roll-out of the policy. The solid horizontal line represents set-up costs of the policy. The dashed lines represent the cumulative benefit of the policy each in each quarter (increase in wage bill, lower deadweight costs of taxation and lower administrative running costs). See text for details.

Figure 8: Comparing Dynamic Effects on IB, JSA and LP Outflow

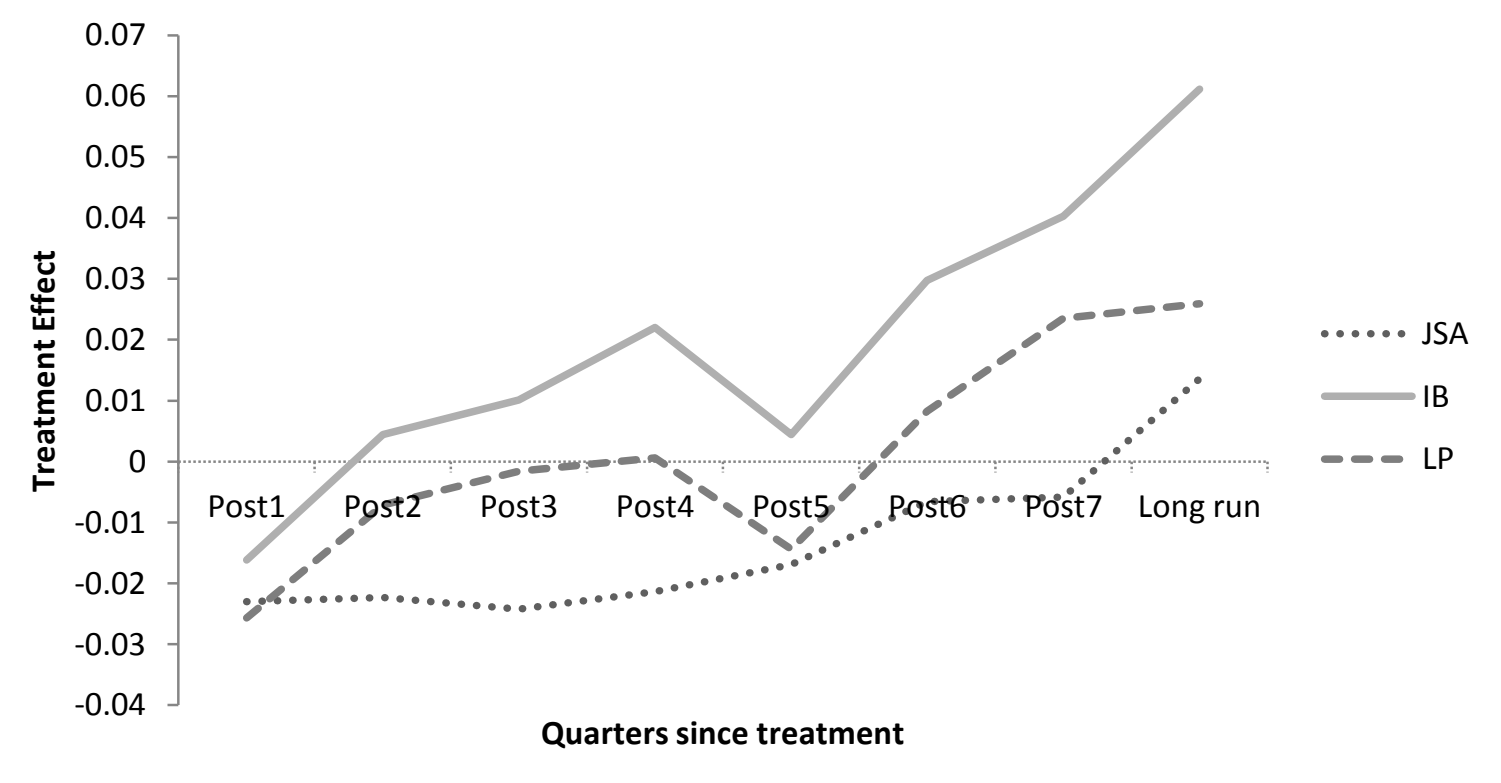

Notes: The sample is a panel of 406 districts from 1999Q3 to 2008Q2. The dependent variable is ln (outflow) for IB for the top line. The middle line represents ln (outflow) for LP and the bottom line for JSA. The three lines denote the estimated coefficients for the dynamic specification in equation (2), plotted together for comparison across the three. Standard errors are clustered at the district level. 
Table 1: Summary Statistics

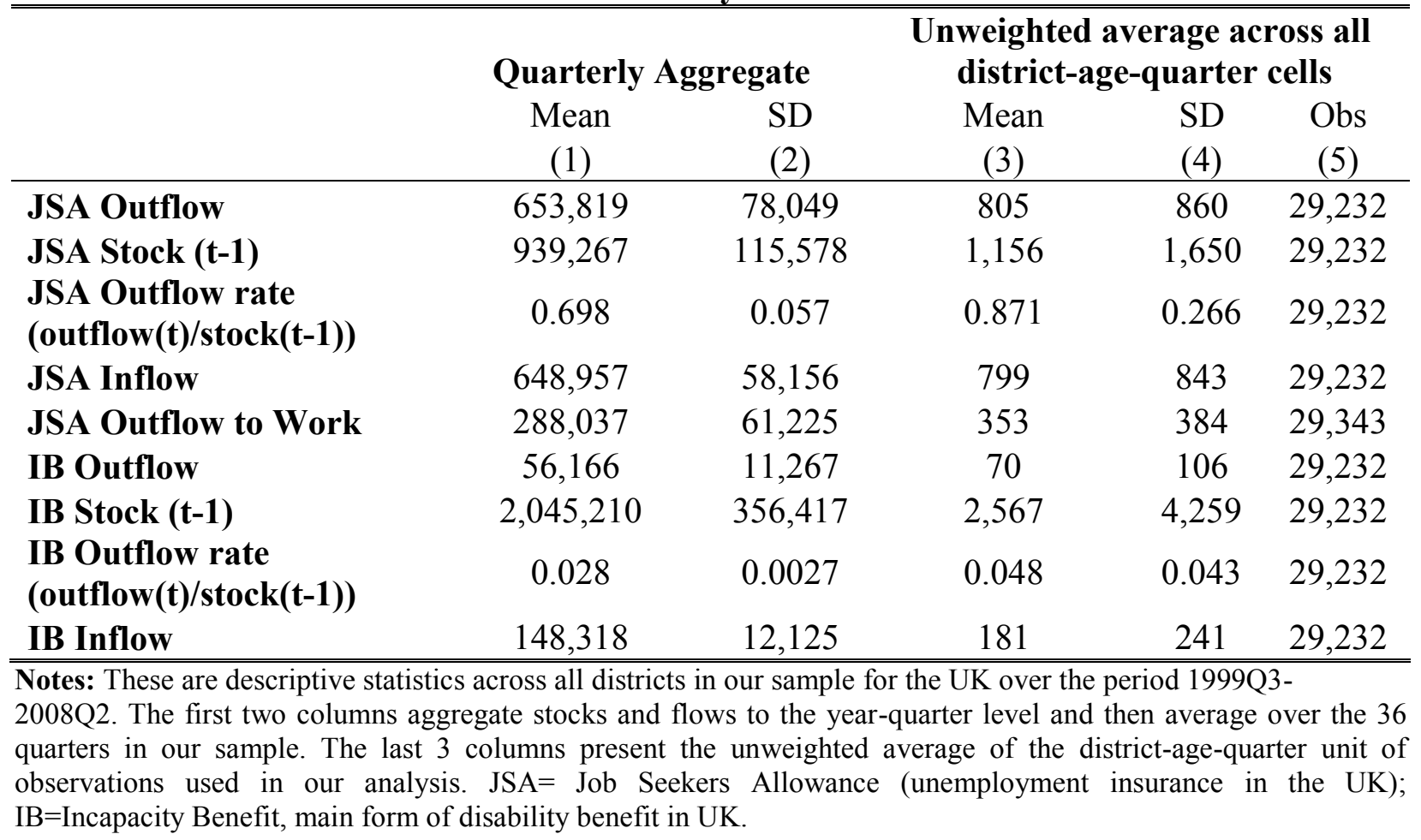

Table 2: Policy Effects on outflow from unemployment (JSA) and disability (IB) benefits Ln(Total Outflow)

\begin{tabular}{lcccccc}
\hline \hline & $(1)$ & $(2)$ & $(3)$ & $(4)$ & $(5)$ & $(6)$ \\
Benefit: & JSA & JSA & JSA & IB & IB & IB \\
\hline $\boldsymbol{D}_{\boldsymbol{i t}}$ & $-0.0153^{* * *}$ & $-0.0152^{* * *}$ & $-0.0152^{* * *}$ & $0.0166^{*}$ & $0.0158^{*}$ & $0.0151^{*}$ \\
& $(0.0054)$ & $(0.0055)$ & $(0.0055)$ & $(0.0089)$ & $(0.0087)$ & $(0.0087)$ \\
$\boldsymbol{l n} \boldsymbol{U}_{\boldsymbol{a i t}-\mathbf{1}}$ & $0.7249 * * *$ & $0.6355^{* * *}$ & $0.6323^{* * *}$ & $0.2495^{* * *}$ & $0.1462^{* * *}$ & $0.3475^{* * *}$ \\
& $(0.0095)$ & $(0.0085)$ & $(0.0100)$ & $(0.0290)$ & $(0.0195)$ & $(0.0314)$ \\
$\boldsymbol{l n} \boldsymbol{U}_{\boldsymbol{a} \text { it }-\mathbf{1}}$ & $-0.0820^{* * *}$ & 0.0072 & 0.0105 & $0.1705^{* * *}$ & $0.2251^{* * *}$ & $0.0502^{*}$ \\
& $(0.0102)$ & $(0.0086)$ & $(0.0097)$ & $(0.0246)$ & $(0.0196)$ & $(0.0256)$ \\
\hline Observations & 29,168 & 29,168 & 29,168 & 26,450 & 26,450 & 26,450 \\
\hline District*Age FE & NO & YES & YES & NO & YES & YES \\
Age*Time FE & NO & NO & YES & NO & NO & YES \\
\hline \hline
\end{tabular}

Notes: Each column estimates equation (1) with the dependent variable as the log of the outflow from benefit during a yearquarter. All regressions control for district, time and age fixed effects. The sample is a panel of 406 districts from 1999Q3 to 2008Q2 and two age groups (18-25 and 26-60). In columns 1, 2 and 3, the dependent variable is ln (outflow) for JSA. In columns 4, 5 and 6, the dependent variable is $\ln$ (outflow) for IB. Standard errors are clustered at the district level. "Post" is a dummy equal to 1 in the post policy period and zero otherwise. $U_{\text {ait-1 }}$ is the lagged stock of individuals on benefits in the same age group (and $U_{a i t-1}$ the same for the other age groups). Time effects are a separate dummy for each quarter by year pair. $* * *$ $\mathrm{p}<0.01,{ }^{* *} \mathrm{p}<0.05,{ }^{*} \mathrm{p}<0.1$ 
Table 3: Effects of policy allowing for dynamics

\begin{tabular}{|c|c|c|c|c|c|c|}
\hline \multicolumn{7}{|c|}{ Dependent Variable: In(Total Outflow) } \\
\hline Quarters after & (1) & (2) & (3) & (4) & (5) & (6) \\
\hline Policy intro & JSA & JSA & JSA & IB & IB & IB \\
\hline \multirow[t]{2}{*}{$D_{i 1}$} & $-0.0234 * * *$ & $-0.0229 * * *$ & $-0.0230 * * *$ & $-0.0203 *$ & -0.0154 & -0.0162 \\
\hline & $(0.0061)$ & $(0.0062)$ & $(0.0062)$ & $(0.0119)$ & $(0.0117)$ & $(0.0117)$ \\
\hline \multirow[t]{2}{*}{$D_{i 2}$} & $-0.0230 * * *$ & $-0.0230 * * *$ & $-0.0230 * * *$ & 0.0052 & 0.0047 & 0.0044 \\
\hline & $(0.0068)$ & $(0.0068)$ & $(0.0068)$ & $(0.0119)$ & $(0.0115)$ & $(0.0115)$ \\
\hline \multirow[t]{2}{*}{$D_{i 3}$} & $-0.0249 * * *$ & $-0.0249 * * *$ & $-0.0249 * * *$ & 0.0112 & 0.0115 & 0.0101 \\
\hline & $(0.0064)$ & $(0.0064)$ & $(0.0064)$ & $(0.0140)$ & $(0.0139)$ & $(0.0139)$ \\
\hline \multirow[t]{2}{*}{$D_{i 4}$} & $-0.0208 * * *$ & $-0.0208 * * *$ & $-0.0208 * * *$ & $0.0254^{*}$ & $0.0223 *$ & $0.0220 *$ \\
\hline & $(0.0061)$ & $(0.0062)$ & $(0.0062)$ & $(0.0130)$ & $(0.0132)$ & $(0.0131)$ \\
\hline \multirow[t]{2}{*}{$D_{i 5}$} & $-0.0166 * *$ & $-0.0166^{* *}$ & $-0.0166 * *$ & 0.0044 & 0.0045 & 0.0044 \\
\hline & $(0.0068)$ & $(0.0069)$ & $(0.0069)$ & $(0.0143)$ & $(0.0139)$ & $(0.0139)$ \\
\hline \multirow[t]{2}{*}{$D_{i 6}$} & -0.0066 & -0.0067 & -0.0067 & $0.0370 * *$ & $0.0309 * *$ & $0.0298 * *$ \\
\hline & $(0.0065)$ & $(0.0066)$ & $(0.0066)$ & $(0.0144)$ & $(0.0138)$ & $(0.0138)$ \\
\hline \multirow[t]{2}{*}{$D_{i 7}$} & -0.0077 & -0.0076 & -0.0076 & $0.0430 * * *$ & $0.0415 * * *$ & $0.0403 * * *$ \\
\hline & $(0.0098)$ & $(0.0099)$ & $(0.0099)$ & $(0.0150)$ & $(0.0150)$ & $(0.0149)$ \\
\hline \multirow[t]{2}{*}{$\boldsymbol{D}_{i L R}$} & 0.0117 & 0.0117 & 0.0117 & $0.0646 * * *$ & $0.0622 * * *$ & $0.0612 * * *$ \\
\hline & $(0.0104)$ & $(0.0105)$ & $(0.0105)$ & $(0.0150)$ & $(0.0144)$ & $(0.0145)$ \\
\hline \multirow{2}{*}{$\ln U_{a i t-1}$} & $0.7237 * * *$ & $0.6344 * * *$ & $0.6312 * * *$ & $0.2589 * * *$ & $0.1552 * * *$ & $0.3572 * * *$ \\
\hline & $(0.0095)$ & $(0.0084)$ & $(0.0100)$ & $(0.0288)$ & $(0.0189)$ & $(0.0308)$ \\
\hline \multirow{2}{*}{$\ln U_{a i t-1}$} & $-0.0832 * * *$ & 0.0060 & 0.0092 & $0.1808 * * *$ & $0.2351 * * *$ & $0.0595 * *$ \\
\hline & $(0.0101)$ & $(0.0085)$ & $(0.0096)$ & $(0.0239)$ & $(0.0191)$ & $(0.0255)$ \\
\hline Observations & 29,168 & 29,168 & 29,168 & 26,450 & 26,450 & 26,450 \\
\hline District*Age FE & $\mathrm{NO}$ & YES & YES & $\mathrm{NO}$ & YES & YES \\
\hline Age*Time FE & $\mathrm{NO}$ & $\mathrm{NO}$ & YES & $\mathrm{NO}$ & $\mathrm{NO}$ & YES \\
\hline F Test & 4.5560 & 4.4980 & 4.4920 & 4.6310 & 4.3260 & 4.2410 \\
\hline p-value & 0.0000 & 0.0000 & 0.0000 & 0.0000 & 0.0001 & 0.0001 \\
\hline
\end{tabular}

Notes: $D_{i j}$ indicates the treatment effect each quarter $j$ after the policy is introduced. Each column estimates equation (2) with the dependent variable as the log of the outflow from benefit during a year-quarter. All regressions control for district, time and age fixed effects. The sample is a panel of 406 districts from 1999Q3 to 2008Q2. In columns 1, 2 and 3, the dependent variable is ln (outflow) for JSA. In columns 4, 5 and 6, the dependent variable is $\ln$ (outflow) for IB. The last row contains the p-value of the F test for the joint significance of the post-treatment dummies. Standard errors are clustered at the district level. $U_{\text {ait-1 }}$ is the lagged stock of individuals on benefits in the same age group (and $U_{a i t-1}$ the same for the other age groups). Time effects are a separate dummy for each quarter by year pair. $* * * \mathrm{p}<0.01, * * \mathrm{p}<0.05, * \mathrm{p}<0.1$ 
Table 4: Pre-treatment Trends in Benefit Outflow?

\begin{tabular}{|c|c|c|c|c|}
\hline \multicolumn{5}{|c|}{ In(Total Outflow) } \\
\hline & (1) & (2) & (3) & (4) \\
\hline & JSA & JSA & IB & IB \\
\hline \multirow{2}{*}{$D_{i t-4}$} & & 0.0013 & & 0.0162 \\
\hline & & $(0.0065)$ & & $(0.0109)$ \\
\hline \multirow{2}{*}{$D_{i t-3}$} & & 0.0039 & & -0.0135 \\
\hline & & $(0.0063)$ & & $(0.0114)$ \\
\hline \multirow[t]{2}{*}{$D_{i t-2}$} & & -0.0021 & & 0.0053 \\
\hline & & $(0.0068)$ & & $(0.0119)$ \\
\hline \multirow[t]{2}{*}{$D_{i t-1}$} & & $-0.0134 *$ & & -0.0010 \\
\hline & & $(0.0079)$ & & $(0.0123)$ \\
\hline \multirow[t]{2}{*}{$D_{i t}$} & $-0.0152 * * *$ & $-0.0168 * *$ & $0.0151 *$ & 0.0160 \\
\hline & $(0.0055)$ & $(0.0069)$ & $(0.0087)$ & $(0.0100)$ \\
\hline \multirow[t]{2}{*}{$\ln U_{a i t-1}$} & $0.6323 * * *$ & $0.6323 * * *$ & $0.3475 * * *$ & $0.3473 * * *$ \\
\hline & $(0.0100)$ & $(0.0100)$ & $(0.0314)$ & $(0.0314)$ \\
\hline \multirow{2}{*}{$\ln U_{a i t-1}$} & 0.0105 & 0.0105 & $0.0502 *$ & $0.0502 *$ \\
\hline & $(0.0097)$ & $(0.0097)$ & $(0.0256)$ & $(0.0256)$ \\
\hline Observations & 29,168 & 29,168 & 26,450 & 26,450 \\
\hline District*Age FE & YES & YES & YES & YES \\
\hline Age*Time FE & YES & YES & YES & YES \\
\hline F Test & & 1.8830 & & 1.3560 \\
\hline p-value & & 0.1130 & & 0.2480 \\
\hline
\end{tabular}

Notes: D indicates the treatment effect each quarter before the policy is introduced. Each column estimates equation (3) with the dependent variable as the log of the outflow from benefit during a year-quarter. All regressions control for district, time and age fixed effects. The sample is a panel of 406 districts from 1999Q3 to 2008Q2. In columns 1 and 2, the dependent variable is $\ln$ (outflow) for JSA. In columns 3 and 4, the dependent variable is $\ln$ (outflow) for IB. The last row contains the p-value of the F test for the joint significance of the pre-treatment dummies. Standard errors are clustered at the district level. $U_{a i t-1}$ is the lagged stock of individuals on benefits in the same age group (and $U_{a i t-1}$ the same for the other age groups). Time effects are a separate dummy for each quarter by year pair $* * * p<0.01,{ }^{* *} \mathrm{p}<0.05,{ }^{*} \mathrm{p}<0.1$ 
Table 5: Analysis of Benefit Inflows

\begin{tabular}{|c|c|c|c|c|}
\hline \multicolumn{5}{|c|}{ Ln(Total Inflow) } \\
\hline & (1) & (2) & (3) & (4) \\
\hline & JSA & JSA & IB & IB \\
\hline$D_{i t}$ & $\begin{array}{c}-0.0063 \\
(0.0085)\end{array}$ & & $\begin{array}{c}-0.0054 \\
(0.0072)\end{array}$ & \\
\hline$D_{i 1}$ & & $\begin{array}{c}-0.0155^{*} \\
(0.0081)\end{array}$ & & $\begin{array}{c}-0.0175^{* *} \\
(0.0080)\end{array}$ \\
\hline$D_{i 2}$ & & $\begin{array}{c}-0.0327 * * * \\
(0.0081)\end{array}$ & & $\begin{array}{c}-0.0179 * \\
(0.0094)\end{array}$ \\
\hline$D_{i 3}$ & & $\begin{array}{c}-0.0170 * * \\
(0.0086)\end{array}$ & & $\begin{array}{c}-0.0068 \\
(0.0088)\end{array}$ \\
\hline$D_{i 4}$ & & $\begin{array}{c}-0.0267 * * * \\
(0.0086)\end{array}$ & & $\begin{array}{c}-0.0064 \\
(0.0093)\end{array}$ \\
\hline$D_{i L R}$ & & $\begin{array}{c}0.0164 \\
(0.0129)\end{array}$ & & $\begin{array}{c}0.0043 \\
(0.0094)\end{array}$ \\
\hline Ln(population) & $\begin{array}{c}0.1441 \\
(0.1278)\end{array}$ & $\begin{array}{c}0.1340 \\
(0.1254)\end{array}$ & $\begin{array}{c}-0.0072 \\
(0.0610)\end{array}$ & $\begin{array}{c}-0.0134 \\
(0.0609)\end{array}$ \\
\hline Observations & 29,096 & 29,096 & 26,727 & 26,727 \\
\hline District*Age FE & YES & YES & YES & YES \\
\hline Age*Time FE & YES & YES & YES & YES \\
\hline
\end{tabular}

Notes: All columns estimate equation (4) with the dependent variable as the inflow into benefits during a yearquarter. All regressions control for district, time and age fixed effects. The sample is a panel of 406 districts from 1999Q3 to 2008Q2. In columns 1-4, the dependent variable is ln (inflow). Standard errors are clustered at the district level. *** $\mathrm{p}<0.01, * * \mathrm{p}<0.05, * \mathrm{p}<0.1$ 
Table 6: Dynamic Policy Effects on JSA and IB Outflows controlling for inflows

\section{Ln(Total Outflow)}

\begin{tabular}{|c|c|c|c|c|c|c|}
\hline & $\begin{array}{r}(1) \\
\text { ISA }\end{array}$ & $\begin{array}{l}(2) \\
\text { ISA }\end{array}$ & $\begin{array}{c}(3) \\
\text { ISA }\end{array}$ & $\begin{array}{l}\text { (4) } \\
\text { IR }\end{array}$ & $\begin{array}{l}\text { (5) } \\
\text { IR }\end{array}$ & $\begin{array}{l}\text { (6) } \\
\text { IR }\end{array}$ \\
\hline \multirow{2}{*}{$D_{i 1}$} & $-0.0235 * * *$ & $-0.0267 * * *$ & $-0.0254 * * *$ & -0.0156 & -0.0174 & -0.0191 \\
\hline & $(0.0054)$ & $(0.0053)$ & $(0.0061)$ & $(0.0118)$ & $(0.0118)$ & $(0.0119)$ \\
\hline \multirow{2}{*}{$D_{i 2}$} & $-0.0149 * * *$ & $-0.0176 * * *$ & $-0.0256 * * *$ & 0.006 & 0.0048 & 0.0014 \\
\hline & $(0.0057)$ & $(0.0057)$ & $(0.0068)$ & $(0.0117)$ & $(0.0119)$ & $(0.0119)$ \\
\hline \multirow{2}{*}{$D_{i 3}$} & $-0.0145 * * *$ & $-0.0178 * * *$ & $-0.0278 * * *$ & 0.0089 & 0.0074 & 0.0039 \\
\hline & $(0.0056)$ & $(0.0055)$ & $(0.0064)$ & $(0.0140)$ & $(0.0139)$ & $(0.0139)$ \\
\hline \multirow[t]{2}{*}{$D_{i 4}$} & $-0.0131 * * *$ & $-0.0119 * *$ & $-0.0237 * * *$ & $0.0291 * *$ & $0.0283^{* *}$ & $0.0255^{*}$ \\
\hline & $(0.0049)$ & $(0.0046)$ & $(0.0062)$ & $(0.0133)$ & $(0.0135)$ & $(0.0134)$ \\
\hline \multirow[t]{2}{*}{$D_{i 5}$} & -0.0073 & -0.006 & $-0.0196 * * *$ & 0.0075 & 0.0062 & 0.0036 \\
\hline & $(0.0059)$ & $(0.0061)$ & $(0.0068)$ & $(0.0141)$ & $(0.0142)$ & $(0.0141)$ \\
\hline \multirow[t]{2}{*}{$D_{i 6}$} & -0.0021 & 0.0022 & -0.0098 & $0.0334 * *$ & $0.0312 * *$ & $0.0293 * *$ \\
\hline & $(0.0053)$ & $(0.0051)$ & $(0.0066)$ & $(0.0138)$ & $(0.0139)$ & $(0.0140)$ \\
\hline \multirow[t]{2}{*}{$D_{i 7}$} & -0.0018 & -0.0015 & -0.0123 & $0.0401 * * *$ & $0.0362 * *$ & $0.0363 * *$ \\
\hline & $(0.0082)$ & $(0.0083)$ & $(0.0099)$ & $(0.0148)$ & $(0.0150)$ & $(0.0152)$ \\
\hline \multirow{2}{*}{$\boldsymbol{D}_{i L R}$} & 0.0064 & 0.0028 & 0.0062 & $0.0589 * * *$ & $0.0503 * * *$ & $0.0547 * * *$ \\
\hline & $(0.0068)$ & $(0.0057)$ & $(0.0103)$ & $(0.0144)$ & $(0.0141)$ & $(0.0145)$ \\
\hline \multirow{2}{*}{$\ln (\operatorname{Inflow})_{i t-1}$} & $0.4252 * * *$ & $0.3765 * * *$ & & $(0.0244)$ & $(0.0286)$ & $(0.0285)$ \\
\hline & $(0.0200)$ & $(0.0147)$ & & $0.0863 * * *$ & $0.0764 * * *$ & \\
\hline \multirow[t]{2}{*}{$\ln (\operatorname{Inflow})_{i t-2}$} & & $0.0773 * * *$ & & $(0.0133)$ & $(0.0132)$ & \\
\hline & & $(0.0109)$ & & & $0.0544 * * *$ & \\
\hline \multirow{2}{*}{$\ln (\operatorname{Inflow})_{i t-3}$} & & $0.0457 * * *$ & & & $(0.0130)$ & \\
\hline & & $(0.0137)$ & & & $0.0344 * * *$ & \\
\hline \multirow[t]{2}{*}{$\ln (\operatorname{Inflow})_{i t-4}$} & & $0.0827 * * *$ & & & $(0.0119)$ & \\
\hline & & $(0.0108)$ & & & $0.0359 * * *$ & \\
\hline \multirow[t]{2}{*}{$\ln U_{a i t-1}$} & $0.3679 * * *$ & $0.3323 * * *$ & $0.6350 * * *$ & & $(0.0121)$ & \\
\hline & $(0.0149)$ & $(0.0117)$ & $(0.0105)$ & $0.3312 * * *$ & $0.2775 * * *$ & $0.3761 * * *$ \\
\hline \multirow[t]{2}{*}{$\ln U_{a^{\prime} i t-1}$} & 0.0069 & $-0.0109 *$ & 0.0033 & $(0.0307)$ & $(0.0344)$ & $(0.0328)$ \\
\hline & $(0.0069)$ & $(0.0059)$ & $(0.0092)$ & $0.0493 * *$ & 0.0231 & 0.0346 \\
\hline Observations & 28352 & 25915 & 25915 & 24402 & 22304 & 22304 \\
\hline District*Age FE & YES & YES & YES & YES & YES & YES \\
\hline Age*Time FE & YES & YES & YES & YES & YES & YES \\
\hline
\end{tabular}

Notes: All columns estimate equation (2) with the dependent variable as the outflow from benefits during a year-quarter. All regressions control for district, time and age fixed effects. The sample is a panel of 406 districts from 1999Q3 to 2008Q2. In columns 1-3, the dependent variable is $\ln$ (outflow) for JSA and the dependent variable in columns 4-6 is the $\ln$ (outflow) for IB. Standard errors are clustered at the district level. $U_{\text {ait-1 }}$ is the lagged stock of individuals on benefits in the same age group (and $U_{a \text { it-1 }}$ the same for the other age groups). Time effects are a separate dummy for each quarter by year pair. ${ }^{* * *} \mathrm{p}<0.01,{ }^{* *} \mathrm{p}<0.05$, $* \mathrm{p}<0.1$ 
Table 7: Dynamic Effects on the Outflow to Work

Ln(Outflow by destination)

\begin{tabular}{|c|c|c|c|c|}
\hline & $\begin{array}{c}(1) \\
\text { To Work }\end{array}$ & $\begin{array}{c}(2) \\
\text { To work }\end{array}$ & $\begin{array}{c}(3) \\
\text { Not to work }\end{array}$ & $\begin{array}{c}\text { (4) } \\
\text { Not to work }\end{array}$ \\
\hline$D_{i t}$ & $\begin{array}{c}-0.0244 * * * \\
(0.0065)\end{array}$ & & $\begin{array}{c}-0.0169 * * * \\
(0.0065)\end{array}$ & \\
\hline$D_{i 1}$ & & $\begin{array}{c}-0.0320 * * * \\
(0.0074)\end{array}$ & & $\begin{array}{c}-0.0402 * * * \\
(0.0118)\end{array}$ \\
\hline$D_{i 2}$ & & $\begin{array}{c}-0.0163 * * \\
(0.0078)\end{array}$ & & $\begin{array}{c}-0.0386 * * * \\
(0.0125)\end{array}$ \\
\hline$D_{i 3}$ & & $\begin{array}{c}-0.0375 * * * \\
(0.0090)\end{array}$ & & $\begin{array}{c}-0.0355^{* * *} \\
(0.0120)\end{array}$ \\
\hline$D_{i 4}$ & & $\begin{array}{c}-0.0218 * * \\
(0.0090)\end{array}$ & & $\begin{array}{c}-0.0403 * * * \\
(0.0119)\end{array}$ \\
\hline$D_{i 5}$ & & $\begin{array}{c}-0.0351 * * * \\
(0.0107)\end{array}$ & & $\begin{array}{c}-0.0253 * * \\
(0.0125)\end{array}$ \\
\hline$D_{i 6}$ & & $\begin{array}{l}-0.0139 \\
(0.0095)\end{array}$ & & $\begin{array}{l}-0.0238 * \\
(0.0130)\end{array}$ \\
\hline$D_{i 7}$ & & $\begin{array}{l}-0.0187 * \\
(0.0107)\end{array}$ & & $\begin{array}{l}-0.0122 \\
(0.0154)\end{array}$ \\
\hline $\boldsymbol{D}_{i L R}$ & & $\begin{array}{l}-0.0082 \\
(0.0107)\end{array}$ & & $\begin{array}{c}0.0084 \\
(0.0145)\end{array}$ \\
\hline $\ln U_{a i t-1}$ & $\begin{array}{c}0.6213 * * * \\
(0.0156)\end{array}$ & $\begin{array}{c}0.6262 * * * \\
(0.0157)\end{array}$ & $\begin{array}{c}0.6305^{* * * *} \\
(0.0121)\end{array}$ & $\begin{array}{c}0.5488 * * * \\
(0.0215)\end{array}$ \\
\hline $\ln U_{a^{\prime} i t-1}$ & $\begin{array}{c}-0.0313 * * \\
(0.0131)\end{array}$ & $\begin{array}{l}-0.0278 * * \\
(0.0129)\end{array}$ & $\begin{array}{l}0.0240 * * \\
(0.0110)\end{array}$ & $\begin{array}{l}0.0319 * \\
(0.0193)\end{array}$ \\
\hline Observations & 28,019 & 28,019 & 28,075 & 28,075 \\
\hline $\begin{array}{l}\text { District*Age FE } \\
\text { Age*Time FE }\end{array}$ & $\begin{array}{l}\text { YES } \\
\text { YES }\end{array}$ & $\begin{array}{l}\text { YES } \\
\text { YES }\end{array}$ & $\begin{array}{l}\text { YES } \\
\text { YES }\end{array}$ & $\begin{array}{l}\text { YES } \\
\text { YES }\end{array}$ \\
\hline
\end{tabular}

Notes: Column 1 estimates equation (1) and column 2 estimates equation (2), both with the dependent variable as the $\log$ of the outflow from benefit to work during a year-quarter. All regressions control for district, time and age fixed effects. The sample is a panel of 406 districts from 1999Q3 to 2008Q2. In columns 1, 2 and 3, the dependent variable is $\log$ (outflow to work) for JSA. The last row contains the p-value of the F test for the joint significance of the post-treatment dummies. Standard errors are clustered at the district level. $U_{a i t-1}$ is the lagged stock of individuals on benefits in the same age group (and $U_{a i t-1}$ the same for the other age groups). Time effects are a separate dummy for each quarter by year pair. $* * * \mathrm{p}<0.01, * * \mathrm{p}<0.05, * \mathrm{p}<0.1$ 
Table 8: Cost-benefit analysis: Steady-state evaluation

\begin{tabular}{|c|c|c|c|}
\hline & \multicolumn{3}{|c|}{ Re-employment earnings } \\
\hline & (1) & (2) & (3) \\
\hline & $\begin{array}{l}\text { Lower bound } \\
\text { (min wage) }\end{array}$ & $\begin{array}{l}\text { Mean re- } \\
\text { employment } \\
\text { earnings }\end{array}$ & $\begin{array}{l}\text { Upper Bound } \\
\text { (median wage) }\end{array}$ \\
\hline 1. Administration cost in old regime (2000 prices) $(£ \mathrm{~m})$ & 3552 & 3552 & 3552 \\
\hline 2. Administration cost in new regime (2000 prices) (£m) & 3314 & 3314 & 3314 \\
\hline 3. Annual saving in administrative costs (£m) & 238 & 238 & 238 \\
\hline 4. Weekly earnings & 122.00 & 250.0 & 360.0 \\
\hline 5. Increase in GDP from wage income $(£ \mathrm{~m})$ & 472.11 & 967.44 & 1393.11 \\
\hline $\begin{array}{l}\text { 6. Deadweight gain }(£ \mathrm{~m}) \\
(40 \% \text { net exchequer saving })\end{array}$ & 113.68 & 204.34 & 121.79 \\
\hline 7. Annual social benefit (2000 prices) (£m) & 823.79 & 1409.77 & 1752.90 \\
\hline 8. Annual social benefit (2010 prices) (£m) & 1013.14 & 1733.82 & 2155.82 \\
\hline 9. PDV of social benefit $(£ \mathrm{~m})$ & 28946.93 & 49537.77 & 61594.92 \\
\hline 10. Total JCPlus Setup Cost (2010 prices) (£m) & 2259.61 & 2259.61 & 2259.61 \\
\hline 11. Net benefit (£m) & 26687.32 & 47278.15 & 59335.31 \\
\hline
\end{tabular}

Notes: We assume that the policy in introduced nationally and we immediately jump to the steady state effects (i.e. we ignore transitional dynamics). The administrative costs are from NAO (2008) and the benefits based on our econometric analysis discussed in the text.

Table 9: Treatment effect in individual waves

\begin{tabular}{|c|c|c|c|c|c|c|c|}
\hline WAVE & 1 & 2 & 3 & 4 & 5 & 6 & Baseline \\
\hline & & & Panel A: L & Total Outf & w) from $\mathrm{JS}$ & & \\
\hline$\overline{D_{i t}}$ & -0.0196 & $-0.0162 *$ & $-0.0147^{*}$ & -0.0121 & -0.0103 & $-0.0107^{*}$ & $-0.0152 * * *$ \\
\hline & $(0.0135)$ & $(0.0093)$ & $(0.0078)$ & $(0.0080)$ & $(0.0073)$ & $(0.0062)$ & $(0.0055)$ \\
\hline $\ln U_{a i t-1}$ & $0.3253^{* * *}$ & $0.3407 * * *$ & $0.3602 * * *$ & $0.3835^{* * *}$ & $0.3916^{* * *}$ & $0.3949 * * *$ & $0.6323 * * *$ \\
\hline & $(0.0182)$ & $(0.0188)$ & $(0.0160)$ & $(0.0158)$ & $(0.0156)$ & $(0.0149)$ & $(0.0100)$ \\
\hline $\ln U_{a} i t-1$ & $0.3373 * * *$ & $0.2825 * * *$ & $0.2594 * * *$ & $0.2272 * * *$ & $0.2248 * * *$ & $0.2219 * * *$ & 0.0105 \\
\hline & $(0.0195)$ & $(0.0187)$ & $(0.0180)$ & $(0.0210)$ & $(0.0224)$ & $(0.0226)$ & $(0.0097)$ \\
\hline Observations & 9727 & 12967 & 16207 & 19448 & 22688 & 25928 & 29168 \\
\hline & & & Panel B: I & (Total Out & ow) from II & & \\
\hline$D_{i t}$ & 0.0114 & 0.0319 & $0.0315^{* *}$ & $0.0295 * *$ & $0.0254 * *$ & $0.0171^{*}$ & $0.0151^{*}$ \\
\hline & $(0.0279)$ & $(0.0202)$ & $(0.0159)$ & $(0.0124)$ & $(0.0108)$ & $(0.0096)$ & $(0.0087)$ \\
\hline $\ln U_{a i t-1}$ & $0.2221 * * *$ & $0.1511 * * *$ & $0.1800 * * *$ & $0.1624 * * *$ & $0.1534 * * *$ & $0.1626^{* * *}$ & $0.3475 * * *$ \\
\hline & $(0.0493)$ & $(0.0407)$ & $(0.0355)$ & $(0.0320)$ & $(0.0308)$ & & $(0.0314)$ \\
\hline $\ln U_{a} i t-1$ & $1.1741^{* * *}$ & $0.7325 * * *$ & $0.3921 * * *$ & $0.4031 * * *$ & $0.4081 * * *$ & $0.3202 * * *$ & $0.0502 *$ \\
\hline & $(0.2219)$ & -0.1647 & $(0.1307)$ & $(0.1118)$ & $(0.0980)$ & $(0.0836)$ & $(0.0256)$ \\
\hline Observations & 7635 & 10435 & 13256 & 16070 & 18844 & 21637 & 26450 \\
\hline
\end{tabular}

Notes: The dependent variable is the log of the quarterly outflow from benefit. All regressions control for interacted district-age and interacted age-time fixed effects. The regressions restrict the post-treatment period to 4 quarters after each wave. The sample is a panel of 406 districts for each wave. In the upper panel the dependent variable is $\ln$ (outflow) for JSA. In the lower panel, the dependent variable is the $\ln$ (outflow) from IB. Standard errors are clustered at the district level. $U_{a i t-1}$ is the lagged stock of individuals on benefits in the same age group (and $U_{a i t-1}$ the same for the other age groups). Time effects are a separate dummy for each quarter by year pair. ${ }^{* * *} \mathrm{p}<0.01,{ }^{* *} \mathrm{p}<0.05, * \mathrm{p}<0.1$. 
Table 10: Treatment Effect on Lone Parents

\begin{tabular}{|c|c|c|c|c|c|}
\hline \multicolumn{6}{|c|}{ Ln(Total Outflow) } \\
\hline & (1) & (2) & (3) & (4) & (5) \\
\hline & LP & LP & LP & LP & LP \\
\hline \multirow{2}{*}{$D_{i t-4}$} & & -0.0120 & 0.0014 & & \\
\hline & & $(0.0112)$ & $(0.0111)$ & & \\
\hline \multirow[t]{2}{*}{$D_{i t-3}$} & & $-0.0302 * * *$ & -0.0166 & & \\
\hline & & $(0.0103)$ & $(0.0106)$ & & \\
\hline \multirow[t]{2}{*}{$D_{i t-2}$} & & -0.0140 & -0.0003 & & \\
\hline & & $(0.0119)$ & $(0.0117)$ & & \\
\hline \multirow[t]{2}{*}{$D_{i t-1}$} & & $-0.0401 * * *$ & $-0.0255 * *$ & & \\
\hline & & $(0.0119)$ & $(0.0121)$ & & \\
\hline \multirow[t]{2}{*}{$D_{i t}$} & $-0.0131 *$ & $-0.0270 * * *$ & $-0.0159 *$ & -0.0096 & \\
\hline & $(0.0067)$ & $(0.0087)$ & $(0.0095)$ & $(0.0073)$ & \\
\hline \multirow[t]{2}{*}{$D_{i 1}$} & & & & & $-0.0265^{* *}$ \\
\hline & & & & & $(0.0110)$ \\
\hline \multirow[t]{2}{*}{$D_{i 2}$} & & & & & -0.0067 \\
\hline & & & & & $(0.0116)$ \\
\hline \multirow[t]{2}{*}{$D_{i 3}$} & & & & & -0.0016 \\
\hline & & & & & $(0.0107)$ \\
\hline \multirow[t]{2}{*}{$D_{i 4}$} & & & & & -0.0020 \\
\hline & & & & & $(0.0118)$ \\
\hline \multirow[t]{2}{*}{$D_{i 5}$} & & & & & -0.0166 \\
\hline & & & & & $(0.0131)$ \\
\hline \multirow[t]{2}{*}{$D_{i 6}$} & & & & & 0.0083 \\
\hline & & & & & $(0.0115)$ \\
\hline \multirow[t]{2}{*}{$D_{i 7}$} & & & & & 0.0211 \\
\hline & & & & & $(0.0143)$ \\
\hline \multirow[t]{2}{*}{$\boldsymbol{D}_{i L R}$} & & & & & $0.0247 * *$ \\
\hline & & & & & $(0.0122)$ \\
\hline \multirow[t]{2}{*}{$\ln U_{a i t-1}$} & $0.4819 * * *$ & $0.4845 * * *$ & $0.5529 * * *$ & $0.5523 * * *$ & $0.5535 * * *$ \\
\hline & $(0.0634)$ & $(0.0632)$ & $(0.0895)$ & $(0.0895)$ & $(0.0898)$ \\
\hline \multirow[t]{2}{*}{$\ln U_{a i t-1}$} & $-0.1921 * * *$ & $-0.1907 * * *$ & $-0.1304 *$ & $-0.1307^{*}$ & -0.1302 \\
\hline & $(0.0553)$ & $(0.0550)$ & $(0.0790)$ & $(0.0790)$ & $(0.0793)$ \\
\hline Observations & 26,378 & 26,378 & 26,378 & 26,378 & 26,378 \\
\hline District*Age FE & YES & YES & YES & YES & YES \\
\hline Age*Time FE & YES & YES & YES & YES & YES \\
\hline District Trend & $\mathrm{NO}$ & $\mathrm{NO}$ & YES & YES & YES \\
\hline F-Test & & 3.894 & 1.757 & & 2.137 \\
\hline P-value & & 0.00408 & 0.137 & & 0.0389 \\
\hline
\end{tabular}

Notes: The dependent variable is the log of the quarterly outflow from benefit. All regressions control for district, time and age fixed effects. The sample is a panel of 406 districts from 1999Q3 to 2008Q2. The dependent variable is $\ln$ (outflow) for LP. The last row contains the p-value of the F test for the joint significance of the pre-treatment dummies. Standard errors are clustered at the district level. $U_{\text {ait }-1}$ is the lagged stock of individuals on benefits in the same age group (and $U_{a i t-1}$ the same for the other age groups). Time effects are a separate dummy for each quarter by year pair. $* * * \mathrm{p}<0.01, * * \mathrm{p}<0.05, * \mathrm{p}<0.1$ 
Table 11: Spillover effects of the policy into neighbouring districts

\begin{tabular}{|c|c|c|c|c|}
\hline \multicolumn{5}{|c|}{ Ln(Total Outflows) } \\
\hline & (1) & (2) & (3) & (4) \\
\hline & JSA & JSA & IB & IB \\
\hline \multirow[t]{2}{*}{$D_{i t}$} & -0.0113 & $-0.0123^{*}$ & $0.0323 * * *$ & $0.0311 * * *$ \\
\hline & $(0.0074)$ & $(0.0073)$ & $(0.0106)$ & $(0.0106)$ \\
\hline \multirow{2}{*}{$N B R_{i t}$} & & 0.0150 & & 0.0146 \\
\hline & & $(0.0092)$ & & $(0.0126)$ \\
\hline \multirow[t]{2}{*}{$\ln U_{a i t-1}$} & $0.6262 * * *$ & $0.6242 * * *$ & $0.3514 * * *$ & $0.3522 * * *$ \\
\hline & $(0.0108)$ & $(0.0110)$ & $(0.0383)$ & $(0.0383)$ \\
\hline \multirow[t]{2}{*}{$\ln U_{a^{\prime} i t-1}$} & 0.0099 & 0.0079 & $0.0673 * *$ & $0.0683 * *$ \\
\hline & $(0.0101)$ & $(0.0102)$ & $(0.0297)$ & $(0.0297)$ \\
\hline Observations & 22,688 & 22,688 & 20,374 & 20,374 \\
\hline
\end{tabular}

Notes: Each column estimates equation (5) with the dependent variable as the log of the quarterly outflow from benefit. All regressions control for district, time and age fixed effects. The sample is a panel of 406 districts from 1999Q3 to 2006Q2. In columns 1 and 2, the dependent variable is ln (outflow) for JSA. In columns 3 and 4, the dependent variable is $\ln$ (outflow) for IB. Standard errors are clustered at the district level. $U_{\text {ait }-1}$ is the lagged stock of individuals on benefits in the same age group (and $U_{a i t-1}$ the same for the other age groups). Time effects are a separate dummy for each quarter by year pair. ${ }^{* * *} \mathrm{p}<0.01, * * \mathrm{p}<0.05, * \mathrm{p}<0.1$ 


\section{Appendices: Not intended for publication unless requested}

\section{A. Appendix Tables and Figures}

Figure A1: Dynamic Effects on JSA Outflow to Work

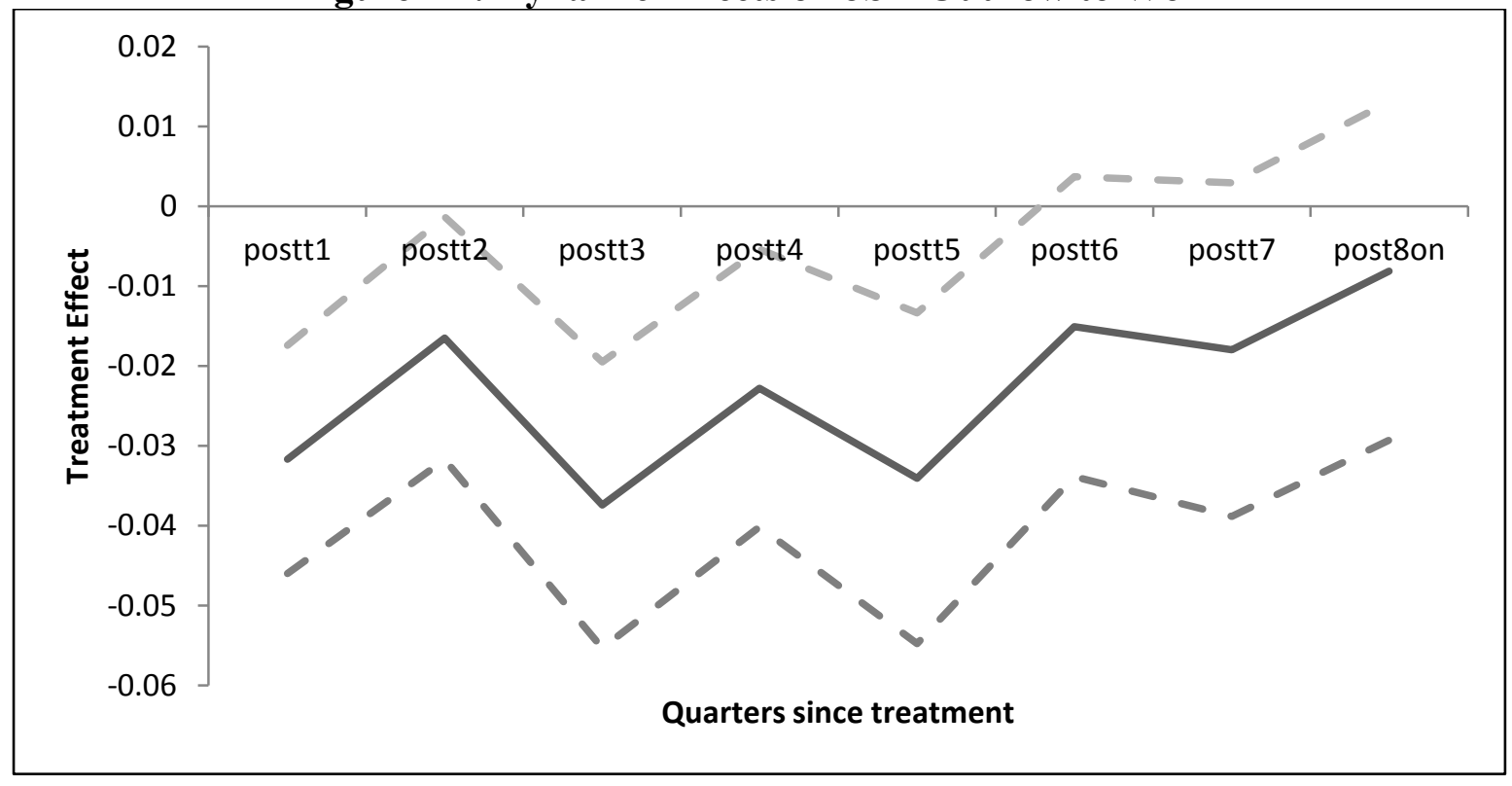

Notes: The sample is a panel of 406 districts from 1999Q3 to 2008Q2. The dependent variable is ln (outflow to work) for JSA. Standard errors are clustered at the district level. The middle line denotes the estimated coefficients for the dynamic specification in Table 7 Column (2). The top and bottom lines denote the $95 \%$ confidence intervals.

Table A1: Job Entry Target points (2002-03)

\begin{tabular}{lc}
\hline \multicolumn{1}{c}{ Client Group } & Points Awarded \\
\hline Disabled People and inactive benefits (IB) & 12 \\
Lone Parents (LP) & 12 \\
New Deal 50+, 25+, Young People & 8 \\
Other long term JSA & 8 \\
Short term unemployed JSA & 4 \\
Employed job-entries & 1 \\
Area-based points & 1 \\
\hline \hline
\end{tabular}

Notes: The second column lists the number of points awarded to a benefit officer for placing a claimant from the corresponding benefit category in column (1) into jobs. 


\begin{tabular}{|c|c|c|}
\hline & $\begin{array}{l}(1) \\
\text { JSA }\end{array}$ & $\begin{array}{l}(2) \\
\text { JSA }\end{array}$ \\
\hline$D_{i t-4}$ & & $\begin{array}{l}-0.0025 \\
(0.0070)\end{array}$ \\
\hline$D_{i t-3}$ & & $\begin{array}{l}-0.0134^{*} \\
(0.0079)\end{array}$ \\
\hline$D_{i t-2}$ & & $\begin{array}{c}-0.0182 * * \\
(0.0086)\end{array}$ \\
\hline$D_{i t-1}$ & & $\begin{array}{c}-0.0550^{* * * *} \\
(0.0099)\end{array}$ \\
\hline$D_{i t}$ & $\begin{array}{c}-0.0545 * * * \\
(0.0056)\end{array}$ & $\begin{array}{c}-0.0710^{* * * *} \\
(0.0117)\end{array}$ \\
\hline $\ln U_{a i t-1}$ & $\begin{array}{c}0.7410 * * * \\
(0.0144)\end{array}$ & $\begin{array}{c}0.7413 * * * \\
(0.0155)\end{array}$ \\
\hline $\ln U_{a i t-1}$ & $\begin{array}{c}0.1418 * * * \\
(0.0167)\end{array}$ & $\begin{array}{c}0.1421 * * * \\
(0.0227)\end{array}$ \\
\hline Observations & 48,351 & 48,351 \\
\hline $\begin{array}{l}\text { District*Age FE } \\
\text { Age*Time FE }\end{array}$ & $\begin{array}{l}\text { YES } \\
\text { YES }\end{array}$ & $\begin{array}{l}\text { YES } \\
\text { YES }\end{array}$ \\
\hline $\begin{array}{l}\text { F Test } \\
\text { p-value }\end{array}$ & & $\begin{array}{c}17.8300 \\
0.0000 \\
\end{array}$ \\
\hline
\end{tabular}

Notes: The above table is limited to the JSA due to data availability. The first column estimates equation (1) and column (2) estimates equation (3) with the dependent variable as the log of the outflow at the office level from JSA during a year-quarter. All regressions control for district, time and age fixed effects. The sample is a panel of 695 offices districts from 1999Q3 to 2008Q2. The last row contains the p-value of the F test for the joint significance of the pre-treatment dummies. Standard errors are clustered at the district level. $U_{a i t-1}$ is the lagged stock of individuals on benefits in the same age group (and $U_{a i t-1}$ the same for the other age groups). Time effects are a separate dummy for each quarter by year pair. ${ }^{* * *} \mathrm{p}<0.01, * * \mathrm{p}<0.05, * \mathrm{p}<0.1$ 
Table A3: Treatment effect in Individual waves (dropping previous waves)

\begin{tabular}{|c|c|c|c|c|c|c|c|}
\hline WAVE & 1 & 2 & 3 & 4 & 5 & 6 & Stacked \\
\hline & \multicolumn{7}{|c|}{ Panel A: Ln(Total Outflow) from JSA } \\
\hline \multirow[t]{2}{*}{$\overline{D_{i t}}$} & -0.0196 & -0.0314 & -0.024 & -0.0234 & -0.0373 & -0.0323 & -0.0333 \\
\hline & 5) & $(0$. & $(0.0$ & $(0$ & $(0.0129)$ & $(0.0$ & $(0$ \\
\hline \multirow[t]{2}{*}{$\ln U_{a i t-1}$} & 0.3253 & 0.341 & 0.3688 & 0.3 & 0.3924 & 0.3 & \\
\hline & $(0.0182)$ & (0.0199) & $(0.0160)$ & $(0.0$ & $(0.0167)$ & $(0.0$ & $(0.0$ \\
\hline \multirow[t]{2}{*}{$\ln U_{a^{\prime} i t-1}$} & 0.3373 & 0.2838 & 0.25 & 0.22 & 0.2127 & 0.205 & 0.2182 \\
\hline & $(0.0195)$ & $(0.0197)$ & $(0.0174)$ & $(0.01$ & $(0.0194)$ & $(0.0202)$ & $(0.0181)$ \\
\hline \multirow[t]{2}{*}{ Observations } & 9727 & 11943 & 13848 & 14889 & 15801 & 15817 & 20216 \\
\hline & \multicolumn{7}{|c|}{ Panel B: Ln(Total Outflow) from IB } \\
\hline \multirow[t]{2}{*}{$D_{i t}$} & 0.0114 & -0.0336 & -0.0015 & -0.0073 & -0.0052 & -0.0288 & -0.0118 \\
\hline & $(0.0279)$ & $(0.0376)$ & $(0.0245)$ & $(0.0202)$ & $(0.0228)$ & $(0.0213)$ & $(0.0137)$ \\
\hline \multirow[t]{2}{*}{$\ln U_{\text {ait }-1}$} & 0.2221 & 0.1464 & 0.1601 & 0.1575 & 0.132 & 0.1214 & 0.1593 \\
\hline & $(0.0493)$ & $(0.0419)$ & $(0.0384)$ & $(0.0361)$ & $(0.0364)$ & $(0.0354)$ & $(0.0331)$ \\
\hline \multirow[t]{2}{*}{$\ln U_{a^{\prime} i t-1}$} & 1.1741 & 0.5537 & 0.356 & 0.4087 & 0.4283 & 0.4151 & 0.3894 \\
\hline & $(0.2219)$ & $(0.1658)$ & $(0.1341)$ & $(0.1219)$ & $(0.1203)$ & $(0.1072)$ & $(0.1055)$ \\
\hline Observations & 7635 & 9556 & 11209 & 12016 & 12594 & 12331 & 16533 \\
\hline
\end{tabular}

Notes: The dependent variable is the log of the quarterly outflow from benefit. All regressions control for interacted district-age and interacted age-time fixed effects. The regressions restrict the post-treatment period to 4 quarters after each wave and drop districts treated in previous waves. In the upper panel the dependent variable is $\ln$ (outflow) for JSA. In the lower panel, the dependent variable is the ln (outflow) from IB. Standard errors are clustered at the district level. $U_{a i t-1}$ is the lagged stock of individuals on benefits in the same age group (and $U_{a i t-1}$ the same for the other age groups). Time effects are a separate dummy for each quarter by year pair. $* * * p<0.01,{ }^{* *} p<0.05, * p<0.1$ 
Table A4: Specification test for dynamic structure

\begin{tabular}{|c|c|c|c|c|c|c|}
\hline & \multicolumn{6}{|c|}{ Ln(Total Outflow from Benefit) } \\
\hline & (1) & (2) & (3) & (4) & $(5)$ & (6) \\
\hline & JSA & JSA & JSA & IB & IB & IB \\
\hline$D_{i 1}$ & $\begin{array}{c}-0.0274 * * * \\
(0.0065)\end{array}$ & $\begin{array}{c}-0.0260 * * * \\
(0.0064)\end{array}$ & $\begin{array}{c}-0.0238 * * * \\
(0.0063)\end{array}$ & $\begin{array}{l}-0.0209 * \\
(0.0114)\end{array}$ & $\begin{array}{l}-0.0190 * \\
(0.0114)\end{array}$ & $\begin{array}{l}-0.0144 \\
(0.0115)\end{array}$ \\
\hline$D_{i 2}$ & $\begin{array}{c}-0.0282 * * * \\
(0.0072)\end{array}$ & $\begin{array}{c}-0.0265 * * * \\
(0.0071)\end{array}$ & $\begin{array}{c}-0.0240 * * * \\
(0.0069)\end{array}$ & $\begin{array}{l}-0.0041 \\
(0.0115)\end{array}$ & $\begin{array}{l}-0.0019 \\
(0.0115)\end{array}$ & $\begin{array}{c}0.0033 \\
(0.0115)\end{array}$ \\
\hline$D_{i 3}$ & $\begin{array}{c}-0.0308 * * * \\
(0.0067)\end{array}$ & $\begin{array}{c}-0.0289 * * * \\
(0.0066)\end{array}$ & $\begin{array}{c}-0.0261 * * * \\
(0.0065)\end{array}$ & $\begin{array}{l}-0.0027 \\
(0.0131)\end{array}$ & $\begin{array}{l}-0.0002 \\
(0.0132)\end{array}$ & $\begin{array}{c}0.0058 \\
(0.0133)\end{array}$ \\
\hline$D_{i 4}$ & & $\begin{array}{c}-0.0255 * * * \\
(0.0065)\end{array}$ & $\begin{array}{c}-0.0222 * * * \\
(0.0063)\end{array}$ & & $\begin{array}{c}0.0079 \\
(0.0121)\end{array}$ & $\begin{array}{c}0.0147 \\
(0.0123)\end{array}$ \\
\hline$D_{i 5}$ & & & $\begin{array}{c}-0.0182 * * * \\
(0.0068)\end{array}$ & & & $\begin{array}{c}0.0011 \\
(0.0138)\end{array}$ \\
\hline$D_{i 6}$ & & & $\begin{array}{l}-0.0085 \\
(0.0065)\end{array}$ & & & $\begin{array}{c}0.0286 * * \\
(0.0134)\end{array}$ \\
\hline $\boldsymbol{D}_{4 L R}$ & $\begin{array}{l}-0.0044 \\
(0.0066)\end{array}$ & & & $\begin{array}{c}0.0353 * * * \\
(0.0105)\end{array}$ & & \\
\hline $\boldsymbol{D}_{5 L R}$ & & $\begin{array}{c}0.0001 \\
(0.0073)\end{array}$ & & & $\begin{array}{c}0.0413 * * * \\
(0.0113)\end{array}$ & \\
\hline $\boldsymbol{D}_{7 L R}$ & & & $\begin{array}{c}0.0078 \\
(0.0089)\end{array}$ & & & $\begin{array}{c}0.0576^{* * *} \\
(0.0127)\end{array}$ \\
\hline $\ln U_{a i t-1}$ & $\begin{array}{c}0.6474 * * * \\
(0.0084)\end{array}$ & $\begin{array}{c}0.6473 * * * \\
(0.0084)\end{array}$ & $\begin{array}{c}0.6469 * * * \\
(0.0084)\end{array}$ & $\begin{array}{c}0.1511 * * * \\
(0.0180)\end{array}$ & $\begin{array}{c}0.1521 * * * \\
(0.0179)\end{array}$ & $\begin{array}{c}0.1547 * * * \\
(0.0177)\end{array}$ \\
\hline $\ln U_{a i t-1}$ & $\begin{array}{l}-0.0013 \\
(0.0085)\end{array}$ & $\begin{array}{l}-0.0015 \\
(0.0085)\end{array}$ & $\begin{array}{l}-0.0019 \\
(0.0085)\end{array}$ & $\begin{array}{c}0.2198 * * * \\
(0.0184)\end{array}$ & $\begin{array}{c}0.2209 * * * \\
(0.0184)\end{array}$ & $\begin{array}{c}0.2239 * * * \\
(0.0183)\end{array}$ \\
\hline Observations & 30,788 & 30,788 & 30,788 & 28,074 & 28,074 & 28,074 \\
\hline District*Age FE & YES & YES & YES & YES & YES & YES \\
\hline Age*Time FE & YES & YES & YES & YES & YES & YES \\
\hline P-value & 0.0000 & 0.0000 & 0.0000 & 0.0003 & 0.0003 & 0.0000 \\
\hline
\end{tabular}

Notes: The dependent variable is the log of the quarterly outflow from benefit. All regressions control for district, time and age fixed effects. The sample is a panel of 406 districts from 1999Q3 to 2008Q2. In columns 1, 2 and 3, the dependent variable is $\ln$ (outflow) for JSA. In columns 4, 5 and 6, the dependent variable is $\ln$ (outflow) for IB. The last row contains the p-value of the $\mathrm{F}$ test for the joint significance of the post-treatment dummies. Standard errors are clustered at the district level. $* * * \mathrm{p}<0.01$, $* * \mathrm{p}<0.05, * \mathrm{p}<0.1$ 
Table A5: Robustness to Weighting by District Level Benefit Caseload

\begin{tabular}{|c|c|c|c|c|}
\hline & \multicolumn{4}{|c|}{ Ln(Total Outflow from Benefit) } \\
\hline & (1) & (2) & (3) & (4) \\
\hline & JSA & JSA & IB & IB \\
\hline$D_{i t}$ & $\begin{array}{c}-0.0251 * * * \\
(0.0060)\end{array}$ & & $\begin{array}{c}0.0091 \\
(0.0088)\end{array}$ & \\
\hline$D_{i 1}$ & & $\begin{array}{c}-0.0288 * * * \\
(0.0077)\end{array}$ & & $\begin{array}{l}-0.0074 \\
(0.0089)\end{array}$ \\
\hline$D_{i 2}$ & & $\begin{array}{c}-0.0317 * * * \\
(0.0079)\end{array}$ & & $\begin{array}{c}0.0029 \\
(0.0116)\end{array}$ \\
\hline$D_{i 3}$ & & $\begin{array}{c}-0.0340 * * * \\
(0.0080)\end{array}$ & & $\begin{array}{l}-0.0096 \\
(0.0107)\end{array}$ \\
\hline$D_{i 4}$ & & $\begin{array}{c}-0.0280 * * * \\
(0.0067)\end{array}$ & & $\begin{array}{c}0.0188 \\
(0.0132)\end{array}$ \\
\hline$D_{i 5}$ & & $\begin{array}{c}-0.0283 * * * \\
(0.0065)\end{array}$ & & $\begin{array}{l}-0.0100 \\
(0.0128)\end{array}$ \\
\hline$D_{i 6}$ & & $\begin{array}{c}-0.0203 * * * \\
(0.0067)\end{array}$ & & $\begin{array}{c}0.0316 * * \\
(0.0140)\end{array}$ \\
\hline$D_{i 7}$ & & $\begin{array}{c}-0.0243 * * \\
(0.0095)\end{array}$ & & $\begin{array}{c}0.0240 \\
(0.0167)\end{array}$ \\
\hline$D_{i L R}$ & & $\begin{array}{c}0.0031 \\
(0.0087)\end{array}$ & & $\begin{array}{c}0.0592 * * * \\
(0.0148)\end{array}$ \\
\hline $\ln U_{a i t-1}$ & $\begin{array}{c}0.5940 * * * \\
(0.0144)\end{array}$ & $\begin{array}{c}0.5898 * * * \\
(0.0139)\end{array}$ & $\begin{array}{c}0.4055 * * * \\
(0.0522)\end{array}$ & $\begin{array}{c}0.3950 * * * \\
(0.0502)\end{array}$ \\
\hline $\ln U_{a i t-1}$ & $\begin{array}{c}0.0560 * * * \\
(0.0135)\end{array}$ & $\begin{array}{c}0.0561 * * * \\
(0.0135)\end{array}$ & $\begin{array}{c}0.0106 \\
(0.0265)\end{array}$ & $\begin{array}{c}0.0384 \\
(0.0239)\end{array}$ \\
\hline Observations & 29,159 & 29,159 & 26,450 & 26,450 \\
\hline $\begin{array}{l}\text { District*Age FE } \\
\text { Age*Time FE }\end{array}$ & $\begin{array}{l}\text { YES } \\
\text { YES }\end{array}$ & $\begin{array}{l}\text { YES } \\
\text { YES }\end{array}$ & $\begin{array}{l}\text { YES } \\
\text { YES }\end{array}$ & $\begin{array}{l}\text { YES } \\
\text { YES }\end{array}$ \\
\hline P-value & & 0.0002 & & 0.0000 \\
\hline
\end{tabular}

Notes: Columns $1 \& 3$ estimate equation (1) and columns $2 \& 4$ estimate equation (2), both with the dependent variable as the $\log$ of the quarterly outflow from benefit. All regressions are weighted by the particular benefit caseload in the district-age group in 1999Q3 (prior to treatment). All estimations control for district, time and age fixed effects. The sample is a panel of 406 districts from 1999Q3 to 2007Q4. In columns 1 and 2 the dependent variable is $\ln$ (outflow) for JSA. In columns 3 and 4 , the dependent variable is $\ln$ (outflow) for IB. The last row contains the p-value of the F test for the joint significance of the post-treatment dummies. Standard errors are clustered at the district level. $U_{a i t-1}$ is the lagged stock of individuals on benefits in the same age group (and $U_{a i t-1}$ the same for the other age groups). Time effects are a separate dummy for each quarter by year pair. ${ }^{* * *} \mathrm{p}<0.01, * * \mathrm{p}<0.05, * \mathrm{p}<0.1$ 
Table A6: Treatment effects on Monthly Outflows from JSA

\begin{tabular}{|c|c|c|}
\hline \multicolumn{3}{|c|}{ Ln(Total Outflow) } \\
\hline & (1) & $(2)$ \\
\hline & JSA & JSA \\
\hline$D_{i t}$ & $\begin{array}{c}-0.0162 * * * \\
(0.0056)\end{array}$ & \\
\hline$D_{i 1}$ & & $\begin{array}{c}-0.0251 * * * \\
(0.0067)\end{array}$ \\
\hline$D_{i 2}$ & & $\begin{array}{c}-0.0205 * * * \\
(0.0072)\end{array}$ \\
\hline$D_{i 3}$ & & $\begin{array}{c}-0.0215 * * * \\
(0.0068)\end{array}$ \\
\hline$D_{i 4}$ & & $\begin{array}{c}-0.0187 * * * \\
(0.0063)\end{array}$ \\
\hline$D_{i 5}$ & & $\begin{array}{c}-0.0217 * * * \\
(0.0076)\end{array}$ \\
\hline$D_{i 6}$ & & $\begin{array}{l}-0.0064 \\
(0.0070)\end{array}$ \\
\hline$D_{i 7}$ & & $\begin{array}{l}-0.0061 \\
(0.0088)\end{array}$ \\
\hline$D_{i L R}$ & & $\begin{array}{c}0.0067 \\
(0.0097)\end{array}$ \\
\hline $\ln U_{a i t-1}$ & $\begin{array}{c}0.7099 * * * \\
(0.0108)\end{array}$ & $\begin{array}{c}0.7090 * * * \\
(0.0109)\end{array}$ \\
\hline $\ln U_{a^{\prime} i t-1}$ & $\begin{array}{c}-0.0620 * * * \\
(0.0103)\end{array}$ & $\begin{array}{c}-0.0629 * * * \\
(0.0102)\end{array}$ \\
\hline Observations & 84,202 & 84,202 \\
\hline $\begin{array}{l}\text { District*Age FE } \\
\text { Age*Time FE }\end{array}$ & $\begin{array}{l}\text { YES } \\
\text { YES }\end{array}$ & $\begin{array}{l}\text { YES } \\
\text { YES }\end{array}$ \\
\hline
\end{tabular}

Notes: Column 1 estimates equation (1) and column 2 estimates equation (2), both with the dependent variable as the log of the outflow from benefit during a year-month. All regressions control for district, time and age fixed effects. The sample is a panel of 406 districts from January 1999 to December 2008. The dependent variable is $\ln$ (outflow) for JSA. Standard errors are clustered at the district level. $U_{\text {ait-1 }}$ is the lagged stock of individuals on benefits in the same age group (and $U_{a i t-1}$ the same for the other age groups). Time effects are a separate dummy for each quarter by year pair. $* * * \mathrm{p}<0.01, * * \mathrm{p}<0.05, * \mathrm{p}<0.1$ 


\section{Appendix A: Data Description}

The empirics are based on three primary sources of data. First, the design of the policy and the list of districts covered under each wave of the rollout was provided by the Department of Work and Pensions. Second, data on other welfare benefits including the key disability benefit, Incapacity Benefit (IB) was sourced directly from the Department of Work and Pensions Tabulation Tool - www.tabulation-tool.dwp.gov.uk/WorkProg/tabtool.html. This provides only quarterly data on the stocks, inflows and outflows of benefit recipients. The data is available for Great Britain (i.e. including England, Wales and Scotland) at the Local Authority Districts level from 1999 Q3 onwards only. The 4 quarters in the dataset are defined as February-April, MayJuly, August-October and November-January. The data can be disaggregated by age and duration.

The second dataset, the Job Seeker's Allowance database was downloaded from www.nomisweb.co.uk. It provides monthly information from 1983 on the stocks, inflows and outflows of recipients' unemployment benefits. The data is available at various geographical levels. We use the data at the Local Authority Districts across Great Britain and there are 406 districts defined on a consistent basis. The data can be disaggregated by age, duration as well as both.

To be consistent across the two datasets, the monthly JSA information is aggregated to the quarterly level. The quarters are defined as February-April, May-July, August-October and November-January. In order to create a quarterly dataset using the monthly information, the flows of each month in a quarter were added up to get the total flows in a quarter. The stocks at the end of a quarter are measured as the stock in the last month of the quarter.

In addition, we use the quarterly micro individual-level panel of the UK Labour Force Survey from 1998 to 2008 to get estimates on the household composition of benefit claimants, mean wages, origins of benefit inflows and destination of benefit leavers. The data is securely provided by the UK Data Service under Special Access License. The quartiles of the weekly earnings distribution were taken from the 2000 New Earnings Survey.

We used digitized boundary datasets and geographic look-up tables corresponding to the census geography of Great Britain, provided by the UK Data Service. We used the boundary data in ArcGIS to illustrate the policy rollout and to define the neighbours of districts.

Finally, the IFS had generously provided benefits estimates using the IFS tax and benefit 
micro-simulation model, TAXBEN. In order to estimate the net exchequer cost of benefit claimants, their estimates assumed that the house rent is $£ 44$ per week (the average among families receiving income support, jobseeker's allowance or incapacity benefit) and that all disposable income is spent on items subject to the standard rate of VAT and no excise duties.

\section{Appendix B}

\section{B1. Steady-state change in the IB rate for the Cost-benefit analysis}

In the cost-benefit analysis we have to consider translating our estimates of flow changes into changes in unemployment and welfare stocks. We obtain the steady state change in the IB rate, based on permanent changes in the IB outflow rate following the introduction of Jobcentre Plus.

Assume there are only two states, employment and IB, and denote by $s$ the inflow rate from employment into IB, and by $f$ the outflow rate from IB into employment. In steady state the IB rate is constant, and flow equilibrium implies that the IB rate (as a fraction of the total population) is given by:

$$
u=\frac{s}{s+f}
$$

The policy has an impact on $f$, leaving $s$ unaffected. The resulting change in the (log) IB rate is given by

$$
d \ln u=-(1-u) d \ln f
$$

The implied change in the number of jobs in steady state is given by:

$$
\Delta e=-u d \ln u=u(1-u) d \ln f
$$

According to our estimates, $d \ln f=\beta-(1-\alpha) d \ln u$, where $\beta$ is the treatment effect estimated by diffs-in-diff, and $\alpha$ is the coefficient on the $\log$ IB stock. The terms in $u$ on the right-hand side of (B1) are evaluated using the actual IB rate in the pre-policy period.

\section{B2. Off steady-state approximation}

At each point in time the unemployment rate evolves according to 


$$
\frac{d u_{t}}{d t}=s_{t}\left(1-u_{t}\right)-f_{t} u_{t}
$$

Solving (B2) forward one period gives:

$$
u_{t}=\gamma_{t} u_{t}^{*}+\left(1-\gamma_{t}\right) u_{t-1}
$$

where $u_{t}^{*}$ denotes steady state unemployment and $\gamma_{t}$ denotes the rate of convergence to it:

$$
\gamma_{t}=1-\exp \left(f_{t}+s_{t}\right)
$$

Using a log-linear approximation to (B3) it can be shown that:

$$
d \ln u_{t}=-\gamma_{t-1}\left(1-u_{t-1}^{*}\right) d \ln f_{t}
$$

where, as above, $d \ln f=\beta-(1-\alpha) d \ln u, u$ is evaluated using the actual IB rate in the previous quarter and $u^{*}$ is evaluated using the (constant) pre-policy inflow rate into benefits obtained from the Labour Force Survey and the time varying outflow rate from benefits as obtained from our estimates.

While the steady-state result stated above is only used for IB predictions (as the steadystate impact of policy on the JSA outflow is close to zero), the off-steady state results are used to obtain predictions for both the IB and JSA rate during the transition to a new steady state. 